\title{
Children with orofacial clefts - \\ dental caries and health-related quality of life
}

\author{
Anna Lena Sundell
}

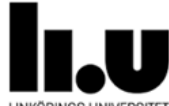

Division of Paediatrics, Department of Clinical and Experimental Medicine, Faculty of Medicine and Health Sciences, Linköping University, Sweden

Oral and Maxillofacial Unit, Section of Dentofacial Orthopedics, University Hospital, Linköping, Sweden

The Institute for Postgraduate Dental Education, Department of Paediatric Dentistry, Jönköping, Sweden

Linköping 2016 
Copyright (C) Anna Lena Sundell

Cover: Sigrid Sundell

Printed in Sweden by Liu-tryck, Linköping, Sweden 2016

ISBN: 978-91-7685-656-7

ISSN: 0345-0082 


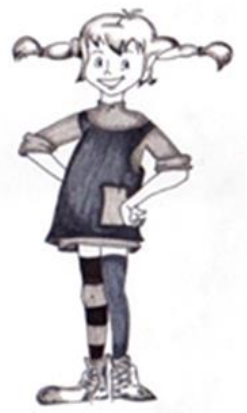

Illustration by Ellen Gustafson

I have never tried that before, so I think I should definitely be able to do that.

Pippi Longstocking, Astrid Lindgren 



\section{Abstract}

Background. The current understanding on caries and enamel developmental defects prevalence and frequency, caries risk, health-related quality life (HRQoL) and stress response in young children with cleft lip and/or palate $(\mathrm{CL} / \mathrm{P})$ are sparse. In this thesis these aspects were investigated in 5- and 10-year-old children with CL/P in comparison to non-cleft children in the same ages.

Design. The studies in this thesis have a cross-sectional case-control design.

Participants. The study group consisted of 139 children with CL/P ( 80 children aged 5 years and 59 aged 10 years) and 313 non-cleft controls (144 children aged 5 years and 169 aged 10 years).

Method. Caries was scored according to International Caries Detection and Assessment System (ICDAS II) and developmental enamel defects were measured as presence and frequency of hypoplasia and hypomineralization. Oral hygiene was assessed using QuigleyHein plaque index. Stimulated saliva samples were analyzed for mutans streptococci, lactobacilli, buffering capacity and secretion rates. Information regarding children's oral hygiene routines, dietary habits and fluoride exposure were collected with questionnaires. Caries risk was evaluated with algorithm-based software, Cariogram while HRQoL was perceived with KIDSCREEN-52. Stress response was analyzed with cortisol concentration in saliva at three different time points using a commercial competitive radioimmunoassay.

Results. Caries prevalence (36\% versus 18\%) and caries frequency (1.2 dmfs versus 0.9 $\mathrm{dmfs}$ ) was significantly higher in 5-year-old children with $\mathrm{CL} / \mathrm{P}$ in comparison to non-cleft controls. In 10-year-olds no significant difference was found between children with CL/P and non-cleft controls in caries prevalence ( $47 \%$ versus $38 \%$ ) or in caries frequency (0.7 DMFS versus $0.5 \mathrm{DMFS}$ ). Children with $\mathrm{CL} / \mathrm{P}$ had significantly higher prevalence of enamel defects, higher counts of salivary lactobacilli and less good oral hygiene. The odds of being categorized with high caries risk were elevated in children with $\mathrm{CL} / \mathrm{P}$. Children with $\mathrm{CL} / \mathrm{P}$ had similar HRQoL and salivary cortisol concentrations as non-cleft controls. However, 10-yearold boys with $\mathrm{CL} / \mathrm{P}$ had significantly higher cortisol concentrations in the evening than noncleft boys.

Conclusions. Preschool children with $\mathrm{CL} / \mathrm{P}$ seem to have more caries in the primary dentition than non-cleft controls. Children with $\mathrm{CL} / \mathrm{P}$ had increased odds of being categorized as high caries risk individuals compared to controls. Some of the contributing factors seem to be higher prevalence of enamel defects, impaired oral hygiene and elevated salivary lactobacilli. Furthermore, as measured with the help of cortisol concentrations in saliva, children with $\mathrm{CL} / \mathrm{P}$ were not more stressed than non-cleft controls and their HRQoL was 
comparable to a European norm population. It appears that regular comprehensive preventive oral care in children with $\mathrm{CL} / \mathrm{P}$ is effective in preventing caries development in permanent teeth. However, children with $\mathrm{CL} / \mathrm{P}$ are at risk of caries development and preventive oral care should be implemented and started earlier than today.

Keywords. children, cleft lip and/or palate, dental caries, caries risk, hypomineralization, hypoplasia, health-related quality of life, cortisol in saliva, stress 


\section{Sammanfattning på svenska}

Syfte. Att studera förekomst och frekvens av karies och emaljdefekter, kariesrisk, hälsorelaterad livskvalitet och stress hos barn med läpp-, käk-, gomspalt (LKG) i jämförelse med jämnåriga barn utan LKG.

Medverkande. 139 barn med LKG (80, 5-åringar och 59, 10-åringar) och 313 barn utan LKG (144, 5-åringar och 169, 10-åringar).

Metod. International Caries Detection and Assessment System (ICDAS-II) användes för att diagnostisera karies. Emaljdefekter registrerades som hypomineralisation eller hypoplasi. Mängden biofilm (plack) undersöktes med modifierat Quigley-Hein Index. Frågeformulär gällande kostvanor, munhygienvanor och fluoranvändning besvarades. Saliv analyserades avseende buffringskapacitet, sekretionshastighet, mängden laktobaciller och mutansstreptokocker. Cariogram användes för att uppskatta kariesrisk. Hälsorelaterad livskvalitet undersöktes med hjälp av KIDSCREEN-52 och stressvaret skattades med hjälp av koncentrationen av kortisol i saliv under ett dygn vid tre olika mättillfällen.

Resultat. 5-åriga barn med LKG hade signifikant ökad kariesförekomst (36 \% respektive $18 \%$ ) och kariesfrekvens (1,2 dmfs respektive $0,9 \mathrm{dmfs})$ i jämförelse med jämnåriga kontrollbarn. Hos 10-åringar hittades ingen signifikant skillnad mellan barn med LKG och kontrollbarn gällande kariesförekomst (47\% respektive $38 \%$ ) och kariesfrekvens (0,7 DMFS respektive 0,5 DMFS). Barn med LKG hade högre förekomst av emaljdefekter, sämre munhygien och ökad halt av laktobaciller. Undersökning med databaserad kariesriskmodell, Cariogram, visade på en ökad kariesrisk hos barn med LKG. Barn med LKG hade i förhållande till kontrollbarnen en likvärdig hälsorelaterad livskvalitet och jämförbar koncentration av stressrelaterad kortisolnivå i saliv. Men, 10-åriga pojkar med LKG hade signifikant högre koncentration av kortisol på kvällen jämfört med jämnåriga pojkar.

Slutsatser. Förskolebarn med LKG har en ökad kariesförekomst jämfört med andra jämnåriga barn. Barn med LKG har ökad förekomst av emaljdefekter, sämre munhygien, ökad halt av laktobaciller i saliv och högre risk att kategoriseras med hög kariesrisk jämfört med barn utan LKG. Utifrån uppmätta koncentrationer av kortisol i saliv är barn med LKG inte mer stressade än barn utan LKG och de har en likvärdig hälsorelaterad livskvalitet i jämförelse med jämnåriga barn. Detta också i jämförelse med en europeisk referenspopulation. Regelbunden förebyggande mun- och tandvård verkar effektivt förebygga karies i permanenta tänder hos barn med LKG. Barn med LKG har en hög kariesrisk och förebyggande vård bör erbjudas tidigare än idag. 
List of papers 


\section{List of papers}

This thesis is based on the following studies, which are referred to in the text by their Roman numerals.

I. Sundell AL, Nilsson AK, Ullbro C, Twetman S, Marcusson A. Caries prevalence and enamel defects in 5- and 10-year-old children with cleft lip and/or palate: A case-control study. Acta Odontol Scand. 2016;74(2):90-5.

II. Sundell AL, Ullbro C, Marcusson A, Twetman S. Comparing caries risk profiles between 5- and 10-year-old children with cleft lip and/or palate and non-cleft controls. BMC Oral Health. 2015 Jul 25;15:85.

III. Sundell AL, Törnhage CJ, Marcusson A. A comparison of health-related quality of life in 5- and 10-year-old Swedish children with and without cleft lip and/or palate. Int $\mathrm{J}$ Paediatr Dent. 2016 Jul 28. doi: 10.1111/ipd.12253.

IV. Sundell AL, Marcusson A, Törnhage CJ. Salivary cortisol rhythms in children with cleft lip and/or palate: a case-control study. Submitted to The Cleft Palate-Craniofacial journal in October 2016.

Reprints were made with permission from the respective publishers. 


\section{Contents}

Introduction

Orofacial cleft

Dental caries

Developmental enamel defects $\quad 5$

Health-related quality of life $\quad 6$

Stress response

Aims of the thesis 11

Materials and methods $\quad 12$

Power analysis 12

Participants $\quad 12$

Clinical examinations $\quad 17$

Samplings and analysis of saliva $\quad 18$

Questionnaires 19

Caries risk profiles and risk category / Cariogram 20

$\begin{array}{ll}\text { Statistical analysis } & 21\end{array}$

Results 23

Dental caries prevalence and frequency 23

Developmental enamel defects prevalence and frequency 24

Caries risk variables 26

Caries risk profiles $\quad 26$

Health-related quality of life $\quad 29$

Stress response $\quad 31$

$\begin{array}{ll}\text { Discussion } & 35\end{array}$

Dental caries prevalence and frequency 35

Developmental enamel defects prevalence and frequency $\quad 36$

Dental caries risk $\quad 36$

Health-related quality of life $\quad 37$

$\begin{array}{ll}\text { Stress response } & 40\end{array}$ 
Methodological considerations $\quad 42$

Participants 43

Dental caries and developmental enamel defects $\quad 44$

Dental caries risk variables and risk profiles $\quad 45$

Health-related quality of life $\quad 45$

Stress response $\quad 46$

$\begin{array}{ll}\text { Ethical considerations } & 49\end{array}$

Main findings and conclusions $\quad 51$

Clinical implications $\quad 52$

Ongoing and future perspectives $\quad 53$

$\begin{array}{ll}\text { Acknowledgements } & 54\end{array}$

$\begin{array}{ll}\text { References } & 56\end{array}$

Original papers I-IV

Appendix 1-5 


\section{Abbreviations and definitions}

The following terminology has been used in this thesis.

AUC Area Under the Curve

AUQUIE Autoquestionnaire Qualitée de Vie Enfant Image

BCLP Bilateral cleft lip and palate

CAR Cortisol Arousal Reaction

CL Cleft lip

CL/P Cleft lip, cleft palate, cleft lip and palate

$\mathrm{CL} \pm \mathrm{P} \quad$ Cleft lip with or without cleft palate

CLP Cleft lip and palate

CP Cleft palate

d/D Primary/permanent decayed tooth surfaces

f/F Primary/permanent filled tooth surfaces due to caries

HRQoL Health-related quality of life

ICDAS International Caries Detection and Assessment System

LHPA Limbic-hypothalamic-pituitary-adrenal regions

$\mathrm{m} / \mathrm{M} \quad$ Primary/permanent missed tooth surfaces due to caries

OHRQoL Oral health-related quality of life

PDS Public dental clinics

PedsQL Pediatric Quality Of Life Inventory

QH Quigley-Hein plaque Index

QoL Quality of life

s/S Primary/permanent tooth surfaces

SF-36 The Short Form 36 Health Survey

UCLP Unilateral cleft lip and palate 
Introduction 


\section{Introduction}

In this thesis caries prevalence and frequency, caries risk factors, caries risk profiles, prevalence and frequency of enamel defects, health-related quality life (HRQoL), and stress response in 5- and 10-year-old children with cleft lip and/or palate (CL/P) are compared to non-cleft children in the same ages.

\section{Orofacial clefts}

A cleft is a fissure or opening that varies from a notch in the lip or to a complete cleft palate extending in to the nasal cavity. In the second and third pregnancy month different structures fuses to form the fetus nose, lip, palate, and maxilla. If the fusion is uncomplete a cleft arises. The cleft can involve the lip, lip and palate, or the palate only. The cleft of the lip can be unior bilateral. See Figure 1a-d.

a

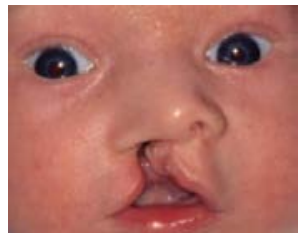

b

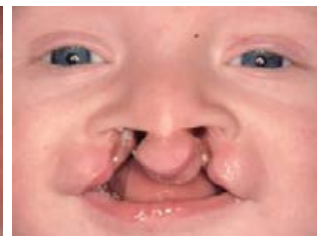

Figure 1a-d. Children with different types of CL/P, before surgical closure of lip and/or palate. $a$; unilateral cleft lip and palate, $b$; bilateral cleft lip and palate, $c$; cleft palate, $d$; unilateral cleft lip and palate.

Orofacial clefts are fairly common congenital malformations. In Sweden, 200 children with either type of orofacial clefts are born each year, giving an incidence of 2/1.000 newborns (Hagberg, Larson et al. 1998). International adoptees and immigrants have increased the prevalence of children with CL/P in Sweden.

The genesis of orofacial clefts can't easily be explained. The cause is most probably multifactorial due to genetic as well as environmental factors (Turvey, Vig et al. 1996, Mitchell 1997). Drugs, smoking, infectious diseases, medications, stress, maternal folic deficiencies, high maternal age, and obesity during pregnancy can increase the risk for cleft development (Mitchell 1997, Coleman and Sykes 2001, Cedergren and Källén 2005, Wehby and Murray 2010, Molina-Solana, Yanez-Vico et al. 2013, Hao, Tian et al. 2015). 
Orofacial clefts are often categorized in cleft lip (CL), isolated cleft palate (CP), unilateral cleft lip and palate (UCLP), and bilateral cleft lip and palate (BCLP). The most common cleft is CP (35\%), followed by CL (30\%), UCLP (20\%), and BCLP (15\%). Sixty-three percent of the children with clefts in Sweden are boys and all types of clefts are more common in boys except for CP that is more common in girls (Hagberg, Larson et al. 1998).

Cleft lip and/or palate (CL/P), especially $\mathrm{CP}$, is frequently present with additional malformations or syndromes. Three hundred named syndromes involves a cleft (Coleman and Sykes 2001). However, syndromes are uncommon and syndromes including cleft diagnosis are even rarer (Sekhon, Ethunandan et al. 2011, Socialstyrelsen 2016). In Sweden 22\% of the children with CL/P have additional malformations (Hagberg, Larson et al. 1998). Anomalies in the facial region, ocular, central nervous, gastrointestinal and urogenital systems are most frequent (Sekhon, Ethunandan et al. 2011).

Children with CL/P need extensive specialist care, involving multi-disciplinary teams from medicine and dentistry. All children with CL/P living in Sweden are treated and followed up at one of six national centers at 5,10, and 19 years of age according to the Swedish National treatment protocol (LKG-registret, kvalitetsregister för uppföljning av läpp- käk- gomspalt 2016). Depending on the type of cleft, treatment includes surgical closure of the lip, surgical closure of the palate, otological and audiological assessment, speech and language therapy, secondary bones grafting if there is a cleft alveolus, dental treatment and orthodontic care.

\section{Dental caries}

Caries is the most common preventable chronic disease worldwide. Dental caries are refereed both to the caries process, the disease itself and the caries lesions, the symptoms formed as a result of the process (Selwitz, Ismail et al. 2007).

Dental caries is defined as demineralization of dental hard tissues due to acid produced by bacteria in the oral biofilm (Selwitz, Ismail et al. 2007). The symptoms range from early signs of demineralization to extensive loss of tooth structure (Figure 2). The first visible clinical sign of caries lesions, is loss of mineral in the outer tooth surface enamel. The lesion has a chalky white appearance and is defined as initial caries (Figure 3a). If the demineralization progresses into inner tooth structure dentine, the lesion appears yellow or brown and may have a cavity, defined as manifest caries (Figure 3b). 


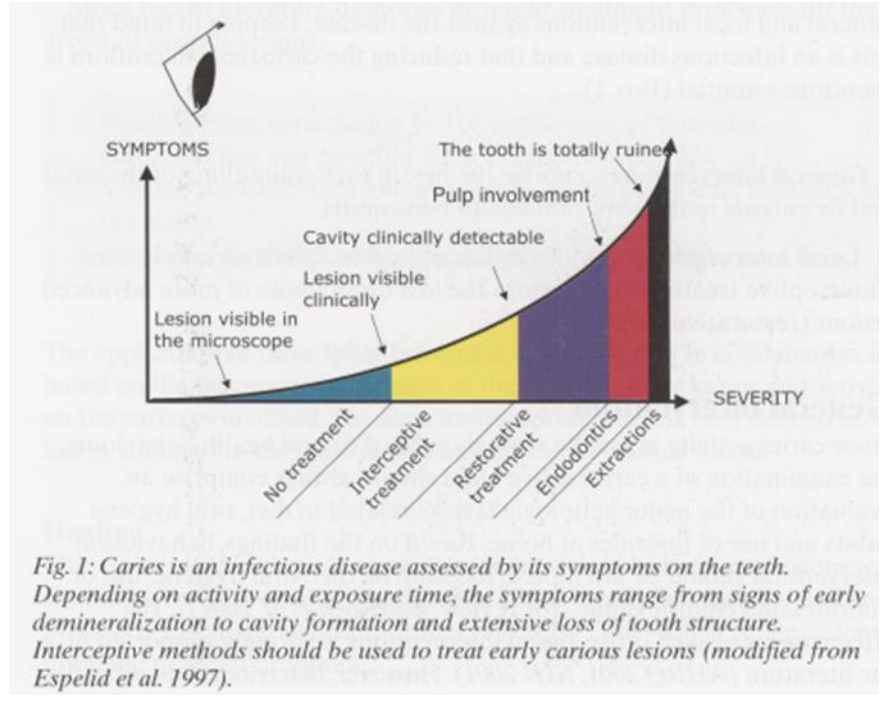

Figure 2. Dental caries symptoms on the teeth. "Consensus Conference on Caries in the Primary Dentition and its Clinical Management”, editors Hugoson, Falk et al. 2002. Reprinted with permission.

a

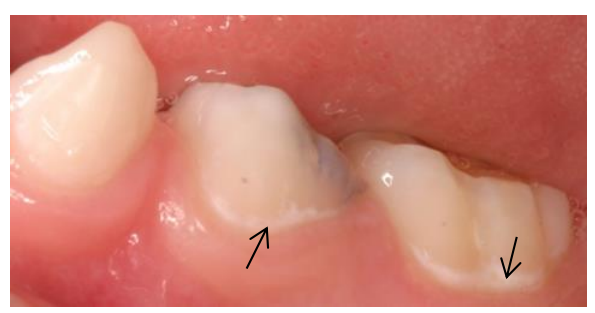

b

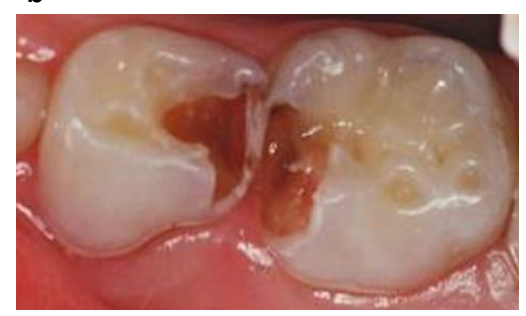

Figure 3a-b. Caries lesions. a; initial caries lesions, b; manifest caries with cavity.

\section{Etiology to dental caries}

Dental caries is a consequence of imbalance between demineralization and remineralization of the dental hard tissue (Moynihan and Petersen 2004, Selwitz, Ismail et al. 2007). The etiology of dental caries is complex and multifactorial (Fejerskov 1997, Selwitz, Ismail et al. 2007). The risk of developing caries is influenced by numerous local factors such as dietary, oral hygiene, microbiology, saliva, tooth morphology, and fluoride exposure. General factors contributing to dental caries are frequent intake of fermentable carbohydrates, especially sugar, together with extensive biofilm (plaque) accumulation. The impact of genetic factors in caries aetiology has been discussed (Wright 2010). High and frequent consumption of sugar changes the balance between and presence of microorganisms in the oral biofilm (Fejerskov 1997, Moynihan and Petersen 2004, Zero 2004, Moynihan and Kelly 2014) increasing the 
amount and the proportion of acid producing bacteria such as mutans streptococci and lactobacilli (van Houte 1980, Loesche 1986). The magnitude of acid production is also depending on oral clearance time of fermentable carbohydrates depending on saliva secretion, orofacial sensibility and function (Ahluwalia, Brailsford et al. 2004, Gabre, Norrman et al. 2005, Dawes 2008). Furthermore, saliva buffering capacity will also affect duration of the acid demineralization of enamel and dentine (Lingström and Moynihan 2003). In addition, development disturbances in dental hard tissues with less mineral in enamel and dentine, increases the vulnerability for demineralization (Oliveira, Chaves et al. 2006, Targino, Rosenblatt et al. 2011, Vargas-Ferreira, Salas et al. 2015). On the contrary, frequent local fluoride exposures will inhibit demineralization and stimulate remineralization of tooth minerals in enamel and dentine (Fejerskov, Thylstrup et al. 1981, Buzalaf, Pessan et al. 2011, ten Cate 2013). Moreover, good oral hygiene, with less amount of biofilm, reduces the amount of acid producing bacteria.

Low socio-economic status and immigrant background are indirect factors related to the occurrence of caries in children living in Sweden and in other Scandinavian countries (Bankel, Eriksson et al. 2006, Christensen, Twetman et al. 2010, Jacobsson, Koch et al. 2011, Ekbäck and Persson 2012). The reason for this seems to be a high consumption of sugary products and poor oral hygiene within these risk groups (Skeie, Riordan et al. 2006, StecksénBlicks, Hasslöf et al. 2014).

\section{Dental caries in children with $C L / P$}

The association between CL/P and dental caries in children is not fully understood. A number of factors can contribute to higher susceptibility such as enamel defects (Maciel, Costa et al. 2005, Gomes, Neves et al. 2009), early colonization of caries-associated microorganisms (Bokhout, van Loveren et al. 1996) and impaired oral hygiene (Dahllöf, Ussisoo-Joandi et al. 1989, Turner, Zagirova et al. 1998, Wong and King 1998, Chopra, Lakhanpal et al. 2014). A prolonged oral clearance time in children with $\mathrm{CL} / \mathrm{P}$ may also contribute to a cariogenic environment (Ahluwalia, Brailsford et al. 2004). Additionally, parents tend to overindulge children with CL/P and offer them sucrose-containing food and snacks as compensation for their medical condition (Johnsen 1984, Johnsen and Dixon 1984). The role and relative importance of the potential risk factors are however not clear.

\section{Caries risk assessment with Cariogram}

Because of the multifactorial etiology to dental caries several risk factors have to be considered when predicting an individual's susceptibility to the disease. Caries risk factors include caries experience, fluoride exposure, extent of biofilm, diet, bacterial and salivary activity and social and behavioral factors.

For caries risk assessment the Cariogram software has been used in this thesis. The model has previously been validated as useful in schoolchildren (Hänsel Petersson, Twetman et al. 2002, Campus, Cagetti et al. 2012) and shows a high sensitivity for caries development in preschool children (Holgerson, Twetman et al. 2009). 


\section{Dental caries prevalence}

In recent decades caries prevalence in Sweden, and in most of the industrialized countries, has decreased (Petersen 2003, Socialstyrelsen 2008, Norderyd, Koch et al. 2015). The presentation of the caries prevalence is higher if initial caries lesions are included in the results. The caries prevalence, including initial caries lesions, has been reported to be $31 \%$ versus 39\% in Swedish 5- and 10-year-olds (Norderyd, Koch et al. 2015). When only manifest cares lesions are including the caries prevalence in Swedish 6- and 12-year-olds has been reported to be $24 \%$ versus $32 \%$ (Socialstyrelsen 2015 ).

Studies from different parts of the world have shown a higher prevalence of dental caries in children with CL/P in comparison with non-cleft controls (Bokhout, Hofman et al. 1996, Hewson, McNamara et al. 2001, Kirchberg, Treide et al. 2004, Al-Wahadni, Alhaija et al. 2005, Stec-Slonicz, Szczepanska et al. 2007, Al-Dajani 2009, Zhu, Xiao et al. 2010, Chopra, Lakhanpal et al. 2014). However, conflicting results have been reported including comprehensive reviews (Paul and Brandt 1998, Lucas, Gupta et al. 2000, Lages, Marcos et al. 2004, Hasslöf and Twetman 2007, Jindal, McMeans et al. 2011, Antonarakis, Palaska et al. 2013). The present knowledge of caries prevalence in Swedish children with CL/P is sparse, and the most recent investigation dates back to the mid-80s (Dahllöf, Ussisoo-Joandi et al. 1989). In the light of the global decline in childhood caries (Petersen, Bourgeois et al. 2005) it was thought of interest to evaluate the current burden of caries among children with $\mathrm{CL} / \mathrm{P}$ living in Sweden.

\section{Dental caries registration}

In the studies in this thesis, caries registrations were performed according to the International Caries Detection and Assessment System (ICDAS-II). The ICDAS criteria allow accurate recording of the severity of carious lesions, through initial lesions to extensive lesions, and have been found to increase the accuracy of caries detection over traditional methods (Kühnisch, Berger et al. 2008).

\section{Developmental enamel defects}

Developmental enamel defects are named as enamel hypoplasia and enamel hypomineralization. Enamel hypoplasia is a quantitative alteration seen as fossae, striae or general absence of the enamel with a changed morphology. A qualitative defect, enamel hypomineralization, is seen as a change in enamel translucency, white, cream, yellow or brown discolorations although with an intact surface morphology. These defects may be caused by environmental and/or hereditary factors (Brook 2009). Malnutrition, neonatal and postnatal infections, maternal use of tobacco, mechanical trauma, and systematic disturbances interfering with tooth formation and mineralization has been described as contributing factors (Salanitri and Seow 2013, Seow 2014). Enamel defects are risk factors for caries development, due to biofilm accumulation and poorly mineralized enamel (Targino, 
Rosenblatt et al. 2011, Vargas-Ferreira, Salas et al. 2015). Moreover, impaired aesthetics, and tooth sensitivity may also be present.

\section{Developmental enamel defects in children with $C L / P$}

The prevalence of enamel defects and other dental anomalies has been reported to be high in children with $\mathrm{CL} / \mathrm{P}$, especially on incisors located adjacent to the cleft (Chapple and Nunn 2001, Maciel, Costa et al. 2005, Gomes, Neves et al. 2009). The etiology of enamel defects in individuals with $\mathrm{CL} / \mathrm{P}$ is not clear. Pathological factors resulting in clefting, both genetic and environmental factors (Malanczuk, Opitz et al. 1999), nutritional and metabolic disturbances due to feeding difficulties, as well as surgical procedures (Dixon 1968, Ranta 1986), have been suggested to influence the development of enamel in children with CL/P. In this thesis, development enamel defects were registered at tooth surface level. Enamel hypomineralization or hypoplasia, illustrated in Figure 4a-b.

a

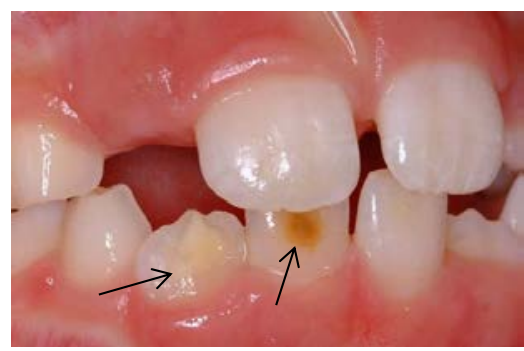

b

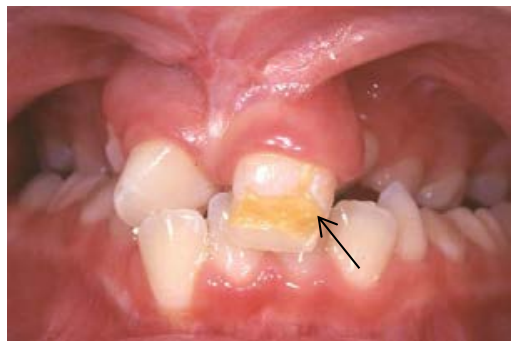

Figure 4a-b. Hypomineralization and hypoplasia in two children with CLP. a; enamel hypomineralization in right central permanent incisors, $b$; enamel hypoplasia in left permanent central incisor and tipping of right central incisor.

\section{Health-related quality of life}

Quality of life (QoL) is defined as an individual's perceptions of his or her position in life in the context of the culture and value systems in which he or she lives in relation to personal goals, expectations, standards, and concerns (The World Health Organization Quality of Life assessment 1995). When personal judgement of one's health and disease is added to QoL, a multidimensional assessment of a person's satisfaction with life, the health-related quality of life (HRQoL) is valuated. Optimal HRQoL is important for anyone, but, in spite of multidisciplinary medical care in children with $\mathrm{CL} / \mathrm{P}$, it can be overlooked by the healthcare providers focusing only on remedying congenital deficiencies.

\section{HRQoL in children with $C L / P$}

Even after surgical treatments instituted early in life some children with CL/P have atypical nasolabial aesthetics and visible scarring, as illustrated in Figure 5. Anomalies in the jaws and 
teeth are frequently presented in children with $\mathrm{CL} / \mathrm{P}$ which also may contribute to aberrant facial appearance. Hearing impairment (Skuladottir, Sivertsen et al. 2015), high frequency of middle ear effusions (Sheahan, Miller et al. 2003), speech impairment (Flynn and Lohmander 2014) together with the burden of comprehensive medical and dental treatment may have consequences for the children's daily life and their perception of HRQoL. During early childhood, children with $\mathrm{CL} / \mathrm{P}$ are not usually aware that they are unlike other children (Chetpakdeechit, Hallberg et al. 2009). Later in childhood they become aware of the cleft and feel dissimilar due to their appearance, speech difficulties, and their need for multiple and sometimes extensive medical and dental treatments. Many of the children with CL/P are being teased for their aberrant facial appearance and hypernasal speech (Hunt, Burden et al. 2006).

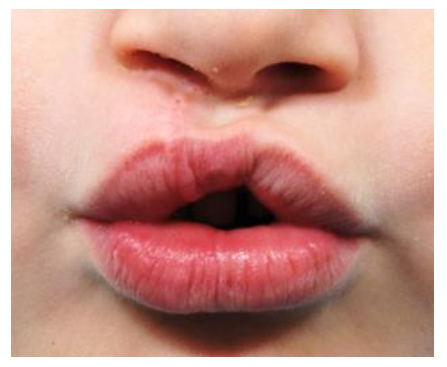

\section{Figure 5. A boy with CLP and minor atypical nasolabial aesthetics and visible scarring.}

Caregivers to children with CL/P often have to take time off work quite often because of the children's healthcare appointments, recurrent middle ear effusions, and surgical treatments. This can have an impact on family income and children's HRQoL as suggested by The World Health Organization (The World Health Organization Quality of Life assessment 1995).

Studies on HRQoL in individuals with $\mathrm{CL} / \mathrm{P}$ have given inconsistent results and numerous different generic instruments have been used. Lower, similar and higher HRQoL have been reported in children and adults with CL/P compared to non-cleft controls (Marcusson, Paulin et al. 2002, Kramer, Gruber et al. 2009, Sagheri, Ravens-Sieberer et al. 2009, Mani, Carlsson et al. 2010, Tannure, Soares et al. 2013). Similar HRQoL have been reported in 8-12-year-old German children with CL/P measured with KINDL, a generic HRQoL instrument for children and adolescents, and in 5-12-year-old Brazilian children with CL/P versus non-cleft controls measuring QoL with Autoquestionnaire Qualitée de Vie Enfant Image (AUQEI), versus noncleft controls (Kramer, Gruber et al. 2009). Also comparable HRQoL have been presented in five of six subscales of the SF-36 (The Short Form 36 Health Survey), while lower score was presented in the subscale mental health, between Swedish adults (20-47-year-olds) with unilateral cleft lip and palate in relation to norm data (Mani, Carlsson et al. 2010). Lower total HRQoL, except for higher score in the dimension "self-esteem", measured with KINDL have been shown in 4-7-year-old German children with CL/P compared to the normal population (Sagheri, Ravens-Sieberer et al. 2009). Also lower HRQoL have been reported in Swedish adults with cleft lip and palate in comparison to controls (Marcusson, Paulin et al. 2002). 
Furthermore, a recently published review and meta-analysis shows that CL/P negatively affect HRQoL in children (2-18-year-olds) and in adults (19-65-year-olds), mainly in psychological health (Queiroz Herkrath, Herkrath et al. 2015).

The knowledge of HRQoL in Swedish children with CL/P is sparse, only studies on adults and adolescents are published. With early surgical treatment and speech therapy, it is nowadays possible to achieve positive aesthetic outcome and optimal result of speech development in children with CL/P. But are treatment outcomes good enough to give children with CL/P an optimal HRQoL in today's society were aesthetic physical appearance and social competence is considered important? As a consequence of this we thought it would be of interest to study health-related quality of life including bullying in children with CL/P in comparison to the situation for non-cleft controls.

\section{The HRQoL instrument KIDSCREEN-52}

The aim in this thesis was to compare HRQoL in children with CL/P in relation to non-cleft controls. The generic HRQoL instrument KIDSCREEN-52 was used instead of a disease specific instrument. The instrument has a broad problem approach and includes 10 dimensions of HRQoL such as physical health, mental health, mood and feelings, autonomy, relationship with parents, financial resources, peers and social support, school environment, bullying, and social acceptance. KIDSCREEN-52 is designed to measure HRQoL in healthy and chronically ill children and measure both positive and negative aspects (Ravens-Sieberer, Gosch et al. 2005).

\section{HRQoL and dental caries}

Dental caries can cause pain and tooth loss that may lead to difficulties in chewing, eating, and drinking (Corrêa-Faria, Paixao-Goncalves et al. 2016). Sleeping problems, irritability, school absenteeism, decline in school performance, and speech impairment have also been described as sequel for severe caries problems (Bönecker, Abanto et al. 2012). As a consequence children may feel aesthetically deprived because of tooth destruction or absence of teeth and may refrain from speaking and avoid smiling/laughing as often as they would like to (Bönecker, Abanto et al. 2012, Gilchrist, Marshman et al. 2015). Caries dental treatment in young ages can be stressful and cause dental fear and behavior management problems (Klingberg 1995). If parents have to take time off from work because of their children's pain, sleeping problems, and dental treatment appointments this may affect the family economy. Consequently high caries experience can influence perceived HRQoL in children. Dental caries has been shown to be strongly associated with low HRQoL in 12-year-old Brazilian children assessed with the generic HRQoL instrument AUQUEI (Paula, Meneghim et al. 2015). No correlation was found in Chinese children aged 3-4 years between caries and HRQoL measured with Pediatric Quality Of Life Inventory (PedsQL) except in the subscale of physical functioning (Lee, McGrath et al. 2010). In 4-10-year-old American children with non-syndromic CL/P lower HRQoL assessed with PedsQL have been associated with higher caries frequency (Cook, Kerins et al. 2016). Studies analyzing correlation between caries and HRQoL in young children are sparse, and studies with Swedish children are even rarer. Does 
caries, even with such low caries frequency as in Sweden, correlate with HRQoL? In this thesis we look for possible correlation between HRQoL, measured with KIDSCREEN-52, and dental caries.

\section{Stress response}

\section{Cortisol rhythms and stress response}

Stress is a sense of distress and results in a normal and an adequate reaction. That results in both a rapid sympathetic-adrenal response and a slower hormonal release response. The rapid reaction increases the release of catecholamines such as adrenalin and noradrenalin from the adrenal medulla and results in increased heart rate, blood pressure, blood glucose, muscle power and alertness. At the same time, there is a slower rate of release of the glucocorticosteroid, cortisol, from the adrenal cortex. The response is initiated from the limbic-hypothalamic-pituitary-adrenal regions (LHPA) with extensive cortisol secretion instantly into blood and with 5-10 minutes delay into saliva. Normally the body makes multiple corrections to achieve an optimal balance, so-called allostasis (McEwen and Seeman 1999). But when stress reactions are frequent and the stress system never returns to relaxation and recovery, the body and soul can enter a waste condition.

\section{Stress response in individuals with $C L / P$}

From birth to adulthood children with CL/P need comprehensive surgical, medical and dental treatments. These multiple treatments can be psychologically stressful for both children and parents. Giving birth to a child with a cleft can lead to emotional reactions, guilt, depression, and posttraumatic stress disorder in the mother (Despars, Peter et al. 2011). High levels of parental stress and parental depression can have long-term effects on the children's stress response and leave the children more susceptible to stress (Essex, Klein et al. 2002, Koch, Ludvigsson et al. 2010, Essex, Shirtcliff et al. 2011).

To our knowledge only two published studies have analyzed salivary cortisol in individuals with CL/P. In infants, morning cortisol concentration did not differ between children with $\mathrm{CL} / \mathrm{P}$ in comparison to healthy non-cleft controls (Mueller, Kalak et al. 2014). Further, in adults, similar cortisol levels are shown between individuals with non-syndromic unilateral cleft lip and palate and non-cleft controls before and after stress induction (Gassling, Holterhus et al. 2012). Therefore, measurement of stress response has been included in one of the studies in this thesis.

\section{Measurements of cortisol}

Cortisol is the end product of the LHPA-axis and it is often used to measure response to stress. The cortisol concentration can be measured in blood, saliva, hair, and urine. The concentration of cortisol in saliva and blood is used to measure the acute stress response (King and Hegadoren 2002, Hellhammer, Wüst et al. 2009), while the concentration in hair 
and urine is used to measure the chronic stress response (Hellhammer, Wüst et al. 2009, Lee do, Kim et al. 2015). In this thesis, stress response is measured with cortisol concentration in saliva. This is the easiest and most convenient way to analyse the acute stress response.

\section{Stress response and dental caries}

Many caries risk factors such as decreased salivary flow rate (Matos-Gomes, Katsurayama et al. 2010), poor oral hygiene (Reddy, Kaul et al. 2012), and calorically dense food intake together with high sugar intake are negatively influenced by stress response (Adam and Epel 2007, Michels, Sioen et al. 2012).

Association between dental caries and salivary cortisol concentration in children has been studied earlier. Pani and Al Odhaib (2013) compared salivary cortisol concentration in 5-yearold children with six or more decayed teeth to caries-free children in the same ages. Cariesfree children had significantly lower morning salivary cortisol concentrations than children with dental caries. Furthermore, morning salivary cortisol concentration was lower three months after caries treatment but still higher than for caries-free children (Pani and Al Odhaib 2013). Similar result has also been reported in 5-10-year-old children (Rai, Hegde et al. 2010). Equivalent results, association between caries and salivary cortisol concentrations have been described in 5-year-old children by Boyce et al. (2010). In addition it is reported that 1014-year-old children with high caries experiences has lower diurnal declines, between morning and afternoon cortisol concentrations in saliva compared to those with low caries experiences (Barbosa, Castelo et al. 2012). However, the stress response to psychological stress, oral prophylaxis, and application of fluoride gel, in 4-5-year-old children with at least one caries lesion have been shown to be in the same magnitude as for caries-free children (Kambalimath, Dixit et al. 2010). Does presence of dental caries correlate to stress response in Swedish children? In this thesis correlation with dental caries and stress response measured with concentration of cortisol in saliva in children with and without CL/P has been analyzed. 


\section{Aims}

The overall aim of the thesis was to investigate caries prevalence and frequency, caries risk, prevalence and frequency of enamel developmental defects, health-related quality of life, and stress related hormone levels in children with $\mathrm{CL} / \mathrm{P}$ in comparison to non-cleft controls.

\section{Specific aims}

\section{Study I}

Are there differences in caries prevalence and frequency, prevalence and frequency of enamel defects, in children with $\mathrm{CL} / \mathrm{P}$ in comparison to age-matched non-cleft controls?

\section{Study II}

Are there differences in caries risk variables and caries risk profiles in children with $\mathrm{CL} / \mathrm{P}$ in comparison to age-matched non-cleft controls?

\section{Study III}

Is there difference in health-related quality of life in children with $\mathrm{CL} / \mathrm{P}$ in comparison to agematched non-cleft controls?

\section{Study IV}

Is there difference in concentration of the stress related hormone cortisol in saliva in children with $\mathrm{CL} / \mathrm{P}$ in comparison to age-matched non-cleft controls? 


\section{Materials and methods}

\section{Power analysis}

Based on regional epidemiology, the caries prevalence among non-cleft children was estimated to vary around $20-40 \%$ in the two age groups. A power calculation with $\alpha=0.05$ and $\beta=0.2$ indicated that 176 children would be required in each group (case versus control) in order to detect a $50 \%$ difference between the groups. In Sweden about 200 children with $\mathrm{CL} / \mathrm{P}$ are born every year and it was considered problematic to include so many children as 176. It was therefore decided to increase the ratio of sample sizes to $1 / 2$ (case versus control), thereby requiring 133 cases with $\mathrm{CL} / \mathrm{P}$ and 266 non-cleft controls.

\section{Participants}

The 10-year-old children gave oral consent, and all parents gave written consent before answering the questionnaires and before clinical examination.

\section{CL/P children}

All 5- and 10-year-old children born with CL/P and attending two regional cleft centers in Sweden (Linköping and Gothenburg) were eligible and invited to participate. The cleft center in Linköping is serving the southeast region of Sweden and the center in Gothenburg is serving the southwest part. Children in the youngest age group were born between October 2006 and December 2008 and children in the older age group were born between December 2001 and December 2003. Two hundred and fifty-eight children and their caregivers were invited to participate. Within this group $22 \%$ of the children had CL, $25 \%$ CP, 34\% UCLP, and $19 \%$ BCLP. Fifty-seven percent of the invited children were boys and $43 \%$ girls. Parents and their children received written information about the study, sent by mail or handed over when they were visiting the cleft center. Non-responders were re-contacted per mail and/or per telephone 2-4 weeks after the first information. The reason for the attrition were no response to the invitation, declined to consent and no cooperation, see Figure 6a.

One hundred thirty-nine children agreed to participate. The distributions of the cleft diagnosis, age, gender and medical conditions for this group are presented in Tables 1-3. Eighty-six children were Swedish natives and nine children were considered having immigrant status (children immigrated to Sweden and children born in Sweden with at least one parent from a foreign country). Forty-four children were adopted from China. They were all adopted in young ages and most of them had primary lip surgery performed before arriving in Sweden. 


\section{Non-cleft controls}

Children in the same ages, born without $\mathrm{CL} / \mathrm{P}$, were randomly selected from six different public dental clinics (PDS) located in the same geographic regions as the CL/P groups. In the southeast region children from the following PDS clinics were recruited: Rosenlund (Jönköping), Tranås, and Mjölby. In the southwest region PDS clinics in Ulricehamn, Falköping, and Södra torget (Borås), see Figure 7. The children were born between January 2002 and December 2003 and January 2007 and December 2008. Two children were adopted, one from China and one from Russia. Two hundred and twenty-six were Swedish natives and 85 children were considered having immigrant status (immigrated to Sweden or were born in Sweden with at least one parent from a foreign country). The age, gender, and children's medical conditions are presented in Tables 2-3. In study IV, further seven 5-year-olds were invited to participate. These children were examined in a pilot study but were not included in the final results in paper I-III. The numbers of participating non-cleft controls see Figure 6 b. 


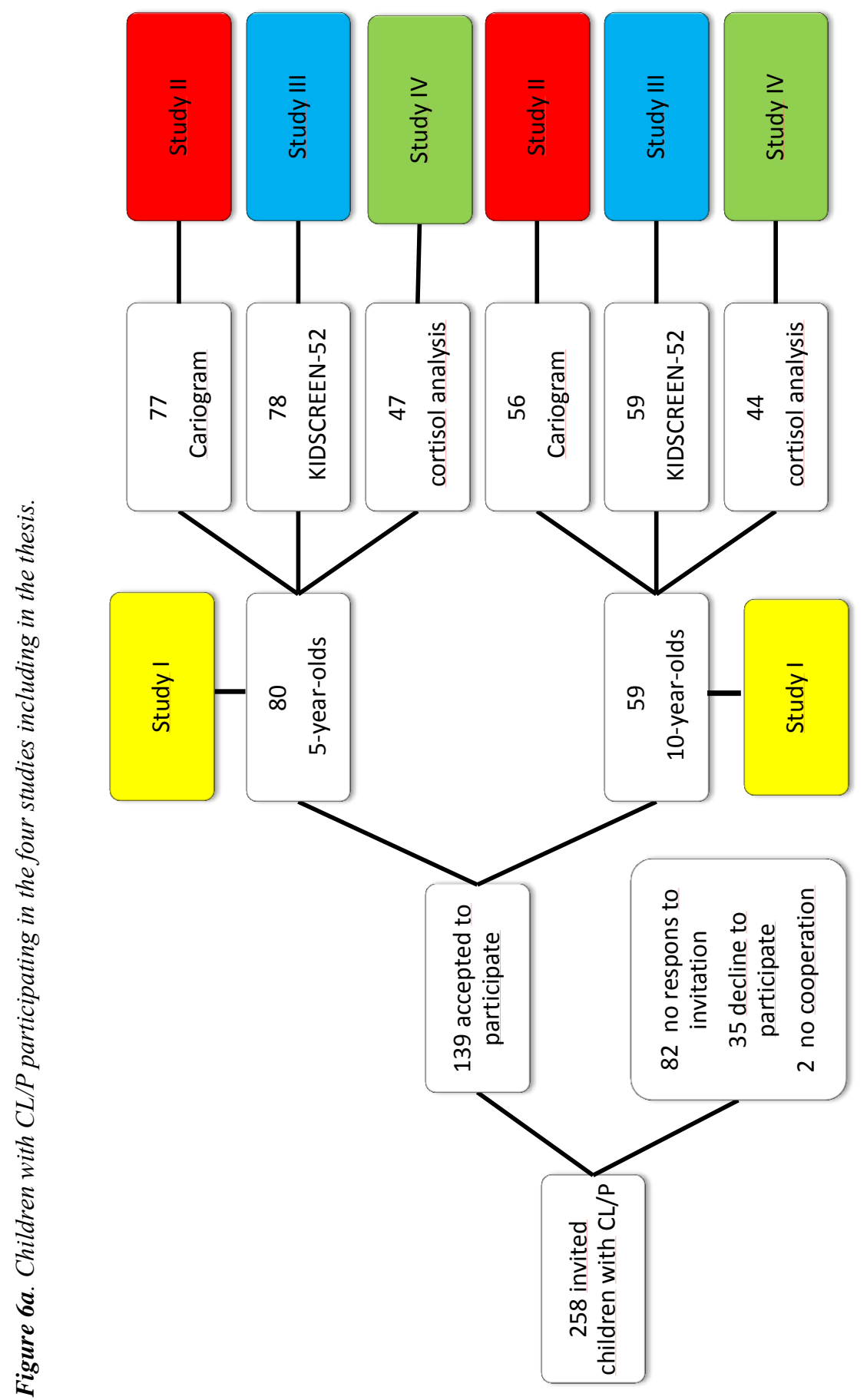




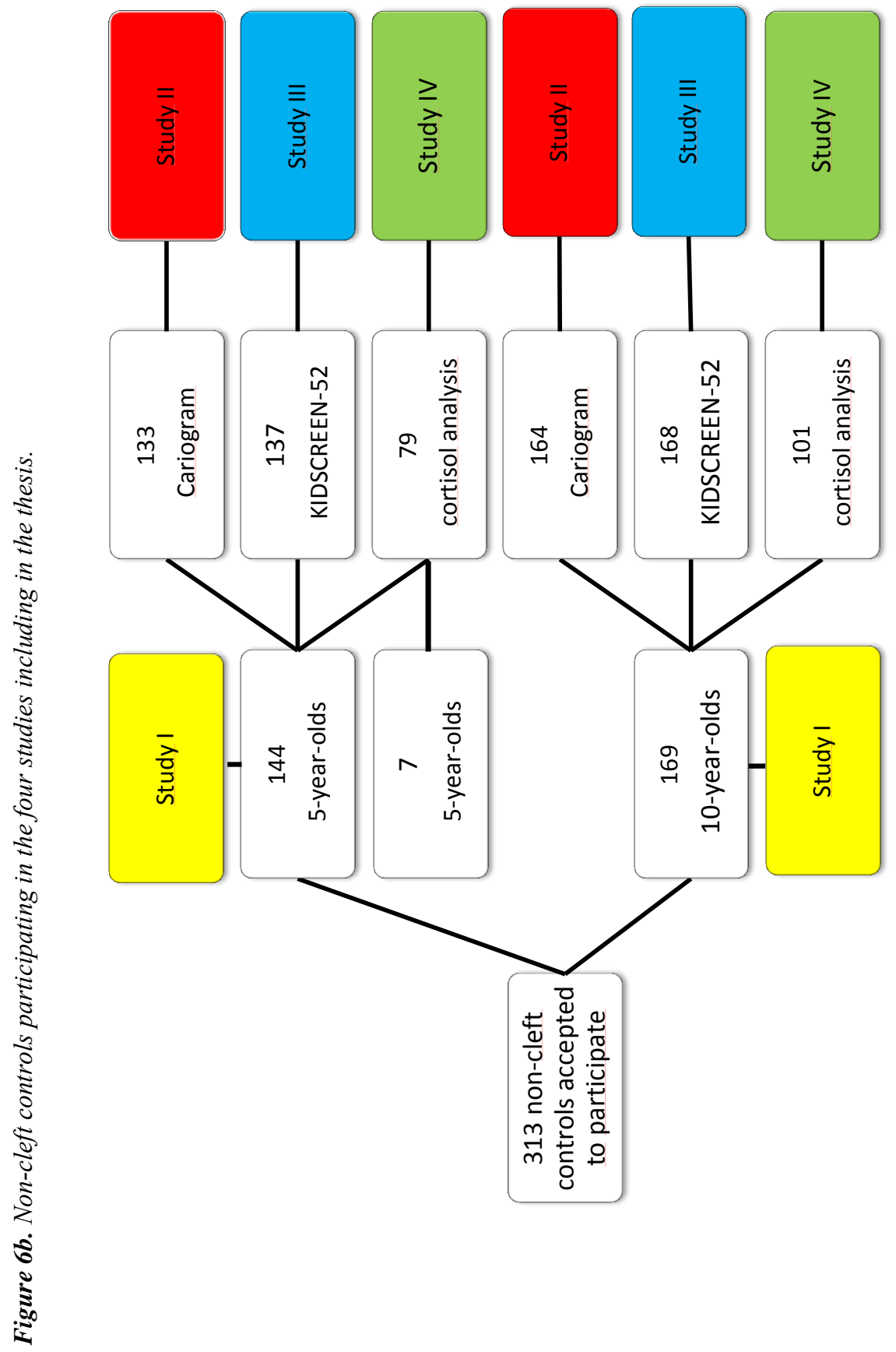




\begin{tabular}{lcc}
\hline Type of cleft & 5-year-olds & 10-year-olds \\
\hline Cleft lip (CL) & 18 & 9 \\
Cleft palate (CP) & 12 & 17 \\
Unilateral cleft lip and palate (UCLP) & 37 & 23 \\
Bilateral cleft lip and palate (BCLP) & 13 & 10 \\
\hline Total CL/P & 80 & 59 \\
\hline
\end{tabular}

Table 1. Distribution of different types of clefts in children with CL/P. Values in the table denote number of children.

\begin{tabular}{lccccc}
\hline & \multicolumn{2}{c}{5 -year-olds } & & \multicolumn{2}{c}{10 -year-olds } \\
\cline { 2 - 3 } \cline { 5 - 6 } & CL/P & $\begin{array}{c}\text { Non-cleft } \\
\text { controls }\end{array}$ & & CL/P & $\begin{array}{c}\text { Non-cleft } \\
\text { controls }\end{array}$ \\
\hline Mean age (SD) & $5.4(0.5)$ & $5.2(0.3)$ & & $10.4(0.6)$ & $10.1(0.3)$ \\
Boys & 46 & 77 & & 34 & 71 \\
Girls & 34 & 67 & & 25 & 98 \\
\hline Total & 80 & 144 & 59 & 169 \\
\hline
\end{tabular}

Table 2. Distribution of gender and age. Values in the table denote number of subjects.

\begin{tabular}{lcc}
\hline Medical conditions & CL/P & Non-cleft controls \\
\hline Asthma & 16 & 22 \\
Heart disease & 2 & 5 \\
Epilepsy & 0 & 3 \\
Diabetes & 0 & 1 \\
Attention deficit/hyperactivity disorder & 2 & 2 \\
Autism & 2 & 1 \\
Pierre Robins sequence & 1 & 0 \\
\hline Total & 23 & 34 \\
\hline
\end{tabular}

Table 3. Distribution of medical conditions in 139 children with $C L / P$ and 313 non-cleft controls. Values in the table denote number of subjects. 


\section{Clinical examinations}

All children were examined from May 2012 through January 2014. The children were examined at a dental clinic near their homes or at the dental clinic at the cleft centers in Linköping or Gothenburg (Figure 7). The clinical inspections were performed in a fully equipped dental chair. All children were examined by one of two pediatric dentists, ALS and AKN.

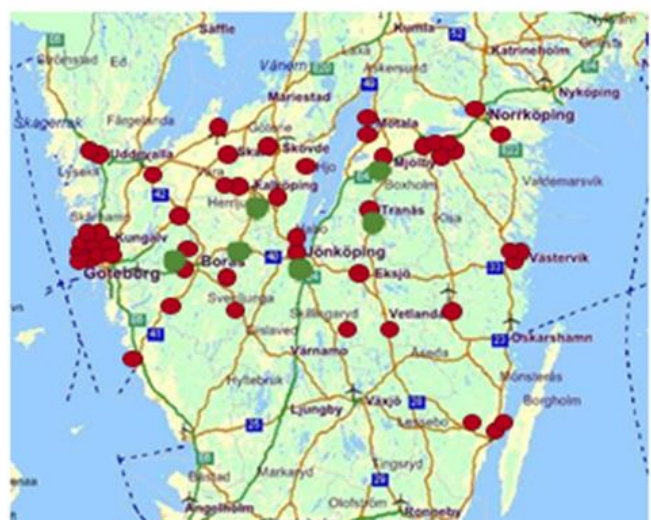

- Dental clinics were children with CL/P have been examined.

- Dental clinics were children without cleft have been examined.

Figure 7. Dental clinics were children have been examined.

\section{Oral hygiene}

The amount of biofilm on the buccal and lingual surfaces of the teeth, in the first and fourth quadrants were scored after staining with erythrosine solution according to the modified Quigley-Hein plaque Index (QH) (Quigley and Hein 1962, Turesky, Gilmore et al. 1970), (Figure 8).

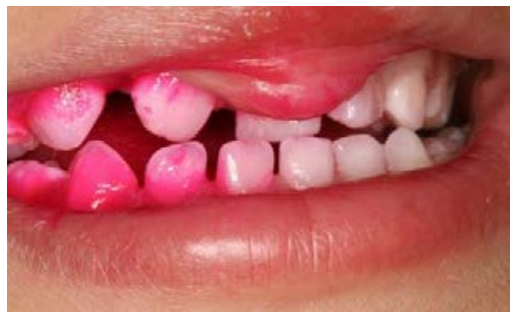

Figure 8. A boy with $C L / P$. Teeth stained with erythrosine.

\section{Dental caries}

The caries scoring was preceded by professional tooth cleaning with rubber cup and prophylactic paste and followed by thorough drying with compressed air. Caries registrations were made according ICDAS-II as described by Pitts and coworkers (Pitts, Ekstrand et al. 2013). The caries lesions were staged as "initial" (ICDAS 1-2), "moderate" (ICDAS 3-4) and 
"extensive" (ICDAS 5-6). If teeth were missing, teeth history were collected from caregivers and children and/or from dental records, and only teeth missing due to caries were taken into account. Primary incisive or canine earlier extracted due to caries was counted as two decayed surfaces and a primary molar as three. Missed tooth surfaces due to caries are referred to in the text and tables as $\mathrm{m} / \mathrm{M}$, decayed tooth surfaces $\mathrm{d} / \mathrm{D}$, filled tooth surfaces due to caries $\mathrm{f} / \mathrm{F}$, tooth surfaces $\mathrm{s} / \mathrm{S}$. Capital letters refers to permanent tooth surfaces and small letters to primary tooth surfaces.

Prior the start of the study the examiners were calibrated using the ICDAS-II criteria and the registrations were validated through a re-examination of 15 children within a period of one month. The intra- and inter-examiner agreement produced an index of positive consensus 0.75 (examiner 1), 0.92 (examiner 2), and 0.97, respectively. The corresponding values for a negative consensus were 0.99 (examiner 1), 1.00 (examiner 2), and 1.00. Many of the children in this reexamination had no clinical sign of caries. This paradox, a strong symmetrical unbalance, often leads to high index of validity but unreasonably low kappa coefficient (Feinstein and Cicchetti 1990). Therefore index of positive and negative consensus was reported as suggested by Cicchetti et al. (1990). Consensus coefficient value of 0.80-1.00 was considered excellent and 0.61 or higher was considered as good (Abramson 1990, Nationella kvalitetsregistret 2016).

\section{Developmental enamel defects}

Enamel defects, assessed as hypomineralization or hypoplasia, were registered on surface level in both primary and permanent teeth. Hypomineralization was registered when the enamel had normal thickness, intact surface but displayed alterations in enamel translucency of variable degree. Both demarcated and diffuse opacity with white, creamy, yellow or brown color were recorded. Hypoplasia was recorded when localized reduction in enamel thickness was present as pits, grooves or when a more extensive part of the tooth surface was missing.

\section{Samplings and analysis of saliva}

\section{Saliva samplings for the assessment of caries risk}

Paraffin-stimulated whole saliva was collected in the dental clinic prior to the dental examination. The sampling was interrupted when $3.5 \mathrm{ml}$ saliva was collected or when the child refused to collaborate any longer. The secretion rate was estimated in milliliter per minute. Buffer capacity (Dentobuff ${ }^{\mathbb{B}}$ Strip) and counts of mutans streptococci (Dentocult ${ }^{\circledR}$ SM-Strip mutans) and lactobacilli (Dentocult ${ }^{\circledR} \mathrm{LB}$ ) were estimated with commercial chair-side tests purchased from Orion Diagnostica (Espoo, Finland). All tests were handled according to the manufacturer's instructions. 


\section{Saliva samplings for analysis of cortisol}

To minimize seasonal influences the collection of saliva was performed during autumn and winter, October 2012 to February 2013 and October 2013 to February 2014. All participants received oral instruction regarding saliva sampling when the child was visiting the dental clinic with their parent. In October written information with a photographic description of saliva collection (Appendix 1) was sent home by mail together with the Salivettes and Sarstedt ${ }^{\mathrm{TM}}$ plastic double lumen tubes, referral to the laboratory and pre-stamped envelopes. If the saliva samples had not been sent to the laboratory within 2 months the participants were contacted by telephone and, if necessary, new information and material for saliva sampling were sent by mail. The saliva was collected using Salivette ${ }^{\mathrm{TM}}$, a cotton-based neutral swab. The child placed the swab in the mouth and chewed without interfering with the swab. When the swab was soaked with saliva, the swab was placed in a sterile tube.

Parents were asked to take a morning sample of their child's saliva at 8 to $9 \mathrm{am}$, before eating breakfast and tooth brushing, on two consecutive days. They were also asked to sample saliva in the evening, around $8 \mathrm{pm}$, the same day as the first morning sample, at least 1 hour after supper, and before tooth brushing. All sampling was performed at home, and the times for the samples were given. All samples were stored in a refrigerator and sent to the laboratory within three days. At the laboratory the sample was centrifuged at room temperature and at $3000 \mathrm{rpm}$ for ten minutes. Salivary cortisol samples were then stored frozen at $-80^{\circ} \mathrm{C}$ in Unilab Skaraborg's Hospital, Skövde, until analysis.

\section{Analysis of cortisol}

The concentration of free cortisol in saliva was analyzed on the same occasion as double tests using a sensitive-validated competitive commercial RIA method, Spectria ${ }^{\mathrm{TM}}$ Cortisol I ${ }^{125}$ (Orion Diagnostica, Landskrona, Sweden). The method has been described previously (Törnhage 2002, Törnhage and Alfvén 2006). For analysis of daytime cortisol rhythm we calculated the salivary cortisol decline (first morning salivary cortisol concentration minus evening salivary cortisol concentration) and the area under the curve from ground $\left(\mathrm{AUC}_{\mathrm{G}}\right)$ and area under the curve increase $\left(\mathrm{AUC}_{\mathrm{I}}\right)$ using the method of Pruessner et al. (2003). AUC is often used to compromise information in repeated measurements over time. In this study $\mathrm{AUC}_{\mathrm{G}}$ is used to estimate the salivary cortisol concentration changes during the same time interval and $\mathrm{AUC}_{\mathrm{I}}$ to estimate the overall concentration during daytime 12+/- 1 hour from morning sample.

\section{Questionnaires}

Children and their custodians were asked to fill out a questionnaire concerning health (Appendix 2), oral hygiene routines, dietary habits, fluoride exposure (Appendix 3 ) and HRQoL (Appendix 4-5). 
For estimation of HRQoL the Swedish version of KIDSCREEN-52 was used. KIDSCREEN52 is a generic worldwide used questionnaire, with self-reported forms available in 33 languages and proxy-versions (for children between 8 and 18 years) available in 29 languages. The questionnaires measures both positive and negative aspects. KIDSCREEN-52 was developed in a European inter-country collaboration network. The identification of dimensions and items, were based on literature reviews, expert consultations and children's focus groups. The questionnaires were after that tested together with health assessments questionnaires. The questionnaires has shown acceptable validity (construct, convergent and discriminant tested) and reliability (Pearson's $r=0.58-0.78$ ) as well as good internal consistency (Cronbach's $\alpha=0.77-0.89$ ) (Ravens-Sieberer, Gosch et al. 2006, RavensSieberer, Herdman et al. 2014). The questions refer to the children's HRQoL over the last week. Each item is scored on a 5-point Likert-type scale $(1=$ no agreement at all, $5=$ total agreement). Following the KIDSCREEN manual, using SPSS syntax available in the compact disc included in the KIDSCREEN questionnaire handbook, the items score of the respective dimensions were summarized. Afterwards the dimensions score were exchanged to Rasch person parameter. Rasch method simultaneously generates measures for individuals' ability to answer the questions and the questions difficulty based on ordinal data. Finally, Rasch values were transformed to T-scores. The Rasch method and T-values are based from twelve European countries. Mean HRQoL T-scores of 50 and standard deviations (SD) \pm 10 are regarded as normal (Ravens-Sieberer, Gosch et al. 2006). Higher values indicate better HRQoL.

KIDSCREEN-52 self-reported version has earlier been used in Swedish studies (Bergström, Modin et al. 2013, Svedberg, Eriksson et al. 2013, Omma and Petersen 2015) as well as the shorter forms of the questionnaire, KIDSCREEN-27 and KIDSCREEN-10 (Bergström, Modin et al. 2013, Hjern, Rajmil et al. 2013, Jervaeus, Kottorp et al. 2013, Jervaeus, Lampic et al. 2014, Berman, Liu et al. 2016).

Parents or caregivers to the 5-year-old children were asked to fill out the proxy version of the KIDSCREEN-52 questionnaire and the 10-year-old children were asked to fill out the selfreported version. If the child or the parents did not understand the questions, the questions were explained by the dental assistant or the dentist. If the child had low reading skills, his or her parent or the dental assistant read the questions aloud. The questionnaires were answered at the dental clinic, in the examination room or in the waiting room. A few parents/children answered the questionnaires at home because of their desire to shorten the visit at the dental clinic.

\section{Caries risk profile and risk category/Cariogram}

Caries risk was evaluated with an algorithm-based software, Cariogram (Bratthall D, Hänsel et al. 2004), built on ten different caries risk factors, with the quest to estimate the relative impact of common caries risk factors immediately involved in the caries process. The program is used to calculate the chance to avoid caries in the near future (Bratthall and Hänsel 
Petersson 2005). The data obtained from the clinical examination, from the questionnaires, and from the salivary tests were entered into the computer program in order to calculate a graphic sector indicating the "chance to avoid caries in the future". The "clinical judgement" was set as 1 and the standard mode was used for country/area and group. Since the model originally was constructed for adults, the clinical scores were modified to fit the present age groups, as follows: previous caries experience, including initial lesions, was scored 1 if the child was caries free, score 2 for $\mathrm{dmfs} / \mathrm{DMFS} 1-2$, and score 3 in the event of $\geq 3 \mathrm{dmfs} / \mathrm{DMFS}$.

Concerning general diseases, medically compromised children with $\mathrm{CL} / \mathrm{P}$, asthma, heart diseases, obesity, diabetes, attention-deficit/hyperactivity disorder, and autism were scored 1. Score 2 was used when two or more related diseases were present. Biofilm amount was scored 0 when QH was $0-1$, score 1 for QH 1.1-2, score 2 for QH 2.1-3.5 and score 3 for QH $3.51-5$. In the younger age group, 5-year-old children, the variable "salivary secretion rate" was omitted due to the difficulty to adequately determine the saliva secretion rate. In the older age group, 10-year-old children, the saliva secretion rate was scored 0 when the secretion rate was over $0.5 \mathrm{ml} / \mathrm{minute}$, scored 1 for $0.49-0.25 \mathrm{ml} / \mathrm{min}$ and scored 2 when under $0.25 \mathrm{ml} / \mathrm{min}$. All other factors were scored according to the Cariogram manual (Bratthall, Hänsel Petersson et al. 2004). The program presents a pie diagram with five sectors in which "circumstances" are based on caries experience and related diseases, "bacteria" is based on amount of biofilm and mutans streptococci, "susceptibility" on fluoride exposure, saliva secretion and saliva buffer capacity, while "diet" is based on diet contents, diet frequency and the amount of lactobacilli. The fifth sector symbolizes the "chance of avoiding caries" in the near future. In this study, only two risk categories were used; "high" $=0-60 \%$ chance to avoid caries, and "low" $=61-100 \%$ chance to avoid caries in the near future.

\section{Statistical analysis}

STATISTICA version 10.0 for Microsoft Software (STATsoft ${ }^{\mathrm{TM}}$, Uppsala, Sweden) and SPSS statistics 20 (IBM, Chicago, IL, USA) were used for all statistical analysis. Descriptive methods were used to describe the study groups; mean, standard deviation (SD), range and median. For non-parametric data, differences between two groups Mann-Whitney U-test was performed and when analysing differences between three or more groups one way-ANOVA, Kruskal-Wallis test were used. In all analysis, level of statistical significance was set at 5\% $(\mathrm{p}<0.05)$.

In study I, a multivariate logistic regression analysis with independent variables: CL/P, health status, born in China and dependent variable: frequency of hypomineralization and hypoplasia in primary and permanent teeth was performed.

In study II, Pearson chi-square test were used to test differences in caries risk variables and Cochrane-Mantel Haenszel test were used to test differences between caries risk profiles. 
In study III, corrections for multiple tests, 10 dimensions of HRQoL, was taken into account using Bonferroni correction.

In study IV, for individual comparisons Wilcoxon's signed rank test was used. Spearman's rank correlation test was used for comparison of salivary concentrations of cortisol and dimensions of HRQoL, gender and age. Multiple linear regression analysis was performed for interactions between concentrations of cortisol and HRQoL, adjusted for age and gender. Bonferroni method for adjustment of mass-significance was used. 


\section{Results}

\section{Dental caries prevalence and frequency}

There were no significant differences in caries prevalence or frequency between children with different types of cleft. Neither between children with CL/P adopted from China and the rest of the $\mathrm{CL} / \mathrm{P}$ children. There was a significant difference in caries prevalence in all children (children with CL/P and non-cleft controls) with Swedish native background (29\%) compared to children with immigrant status (41\%). Furthermore, when total caries frequency (in both primary and permanent teeth) was compared between all children (children with CL/P and non-cleft controls) with immigrant status and children with Swedish natives there was a statistical difference, $\mathrm{p}=0.009$.

\section{Dental caries prevalence and caries frequency in 5-year-olds}

The caries prevalence was $36 \%$ in children with CL/P compared to $18 \%$ in non-cleft controls. The difference was statistically significant. Children with $\mathrm{CL} / \mathrm{P}$ had significantly more caries lesions (d1-6mfs) than non-cleft controls. This was also seen at the dentin level ( $\mathrm{d} 3-4 \mathrm{mfs})$ and for extensive dentin lesions (d5-6mfs) but not on the enamel level (d1-2mfs) (Figure 9a). There was a significantly difference in the relative proportion of caries lesions located in the primary anterior teeth (incisors) in children with CL/P (36\%) compared to non-cleft controls (19\%). For standard deviation see Paper I.

\section{Dental caries prevalence and caries frequency in 10-year-olds}

Caries prevalence in the permanent teeth was $47 \%$ in children with CL/P and $38 \%$ in non-cleft controls. The difference was not statistically significant. There was no statistically difference in caries frequency in this age-group (Figure 9b). For standard deviation see Paper I. 


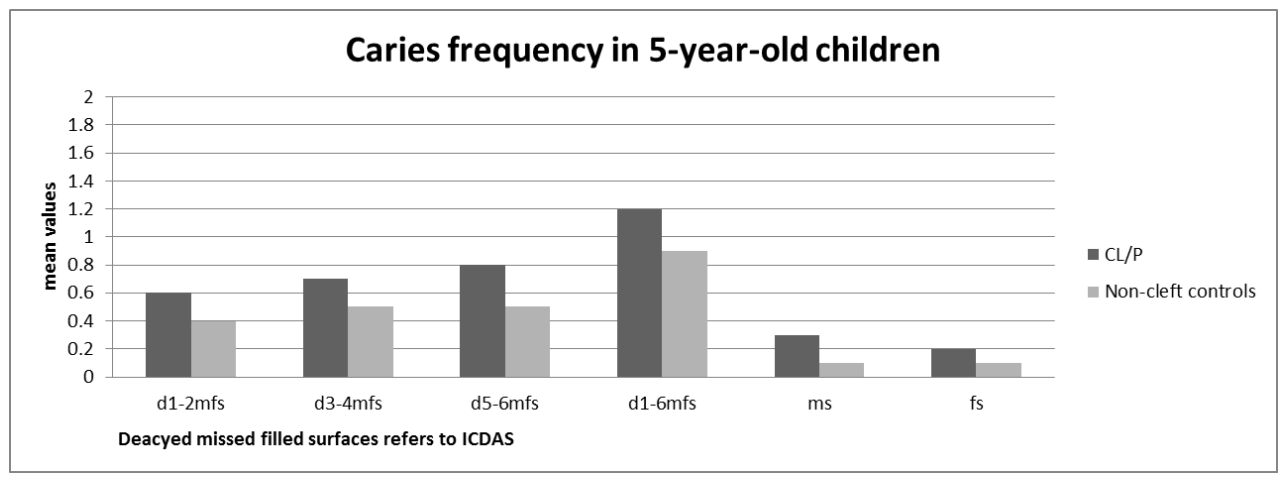

Figure 9a. Caries frequency in 5-year-old children.

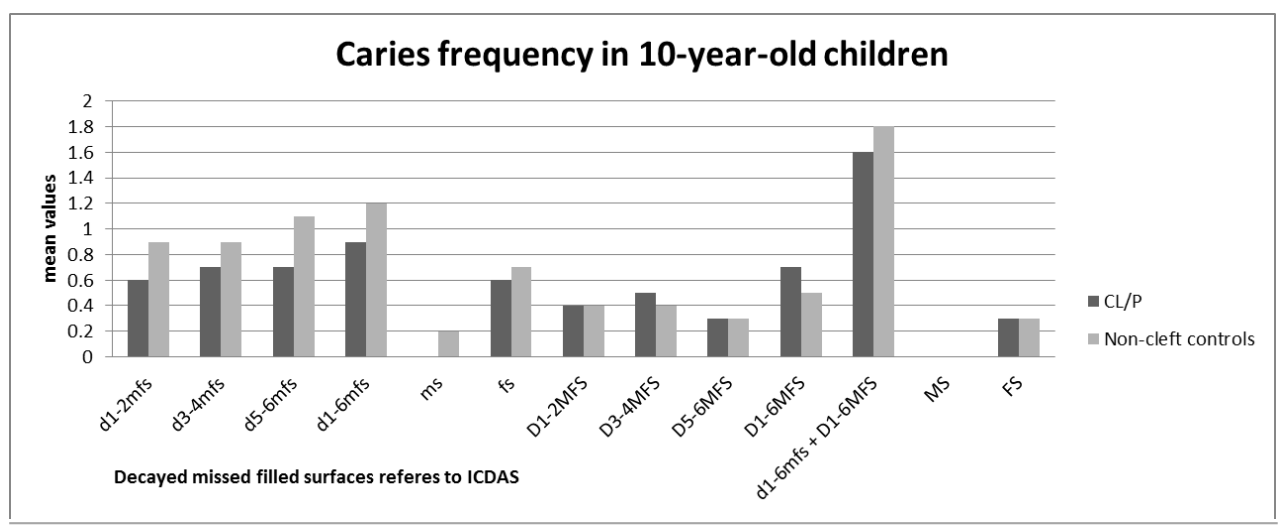

Figure 9b. Caries frequency in 10-year-old children.

\section{Developmental enamel defects prevalence and frequency}

There was a statistical difference between children with CL/P and non-cleft controls in prevalence of enamel hypomineralization/hypoplasia both in 5-year-olds, primary teeth, and 10 -year-olds, permanent teeth. The prevalence in children with CL/P was $61 \%$ in 5 -year-olds and $75 \%$ in 10 -year-olds, and corresponding values for non-cleft controls $26 \%$ versus $47 \%$. In Table $4 a-b$ the frequency in relation to the location is shown. Enamel defects were more common in central incisors, and this pattern was more distinct in the permanent than in the primary dentition.

No significant differences in prevalence or frequency in enamel defects were found between children with different types of cleft. Not either when children with CL were compared with children with cleft involving the palate.

In primary, but not in permanent teeth, there was a significant difference between total numbers of hypomineralization and hypomineralization/hypoplasia between children with 
$\mathrm{CL} / \mathrm{P}$ adopted from China and the rest of the children with $\mathrm{CL} / \mathrm{P}$. In the multivariate logistic regression analysis, the independent factor $\mathrm{CL} / \mathrm{P}$ significantly increased $(\mathrm{p}<0.05)$ the risk for hypomineralization and hypoplasia in both primary and permanent teeth.

\begin{tabular}{|c|c|c|c|c|c|}
\hline \multirow[t]{2}{*}{ Enamel defects } & \multicolumn{2}{|c|}{$\begin{array}{l}\mathrm{CL} / \mathrm{P} \\
\mathrm{n}=80\end{array}$} & \multicolumn{2}{|c|}{$\begin{array}{l}\text { Non-cleft controls } \\
\qquad \mathrm{n}=144\end{array}$} & \multirow{2}{*}{$\begin{array}{c}P \\
(\leq 0.05)\end{array}$} \\
\hline & Mean & $\mathrm{SD}$ & Mean & SD & \\
\hline $\begin{array}{l}\text { Hypomineralization } \\
\text { incisives }\end{array}$ & 0.5 & 1.0 & 0.2 & 0.8 & 0.00 \\
\hline $\begin{array}{l}\text { Hypomineralization } \\
\text { canines and molars }\end{array}$ & 0.3 & 0.8 & 0.2 & 0.6 & NS \\
\hline Hypoplasia incisives & 0.2 & 0.6 & 0.0 & 0.0 & 0.00 \\
\hline $\begin{array}{l}\text { Hypoplasia canines } \\
\text { and molars }\end{array}$ & 0.4 & 1.1 & 0.1 & 0.2 & 0.00 \\
\hline $\begin{array}{l}\text { Total hypomineralization } \\
\text { and hypoplasia }\end{array}$ & 2.0 & 2.7 & 0.8 & 1.6 & 0.00 \\
\hline
\end{tabular}

Table 4a. Enamel defects, hypomineralization and hypoplasia, in primary teeth in 5-year-old children.

\begin{tabular}{|c|c|c|c|c|c|}
\hline \multirow[t]{2}{*}{ Enamel defects } & \multicolumn{2}{|c|}{$\begin{array}{l}\mathrm{CL} / \mathrm{P} \\
\mathrm{n}=59\end{array}$} & \multicolumn{2}{|c|}{$\begin{array}{l}\text { Non-cleft controls } \\
\qquad \mathrm{n}=169\end{array}$} & \multirow{2}{*}{$\begin{array}{c}P \\
(\leq 0.05)\end{array}$} \\
\hline & Mean & $\mathrm{SD}$ & Mean & $\mathrm{SD}$ & \\
\hline $\begin{array}{l}\text { Hypomineralization } \\
\text { incisives }\end{array}$ & 1.7 & 2.0 & 1.3 & 2.1 & 0.01 \\
\hline $\begin{array}{l}\text { Hypomineralization } \\
\text { molars }\end{array}$ & 0.8 & 1.4 & 0.5 & 1.2 & 0.03 \\
\hline Hypoplasia incisives & 0.4 & 0.8 & 0.0 & 0.1 & 0.00 \\
\hline Hypoplasia molars & 0.1 & 0.4 & 0.0 & 0.1 & NS \\
\hline $\begin{array}{l}\text { Total hypomineralization } \\
\text { and hypoplasia }\end{array}$ & 3.0 & 3.0 & 1.8 & 2.7 & 0.00 \\
\hline
\end{tabular}

Table $4 \boldsymbol{b}$. Enamel defects, hypomineralization and hypoplasia, in permanent teeth in 10-year-old children. 


\section{Caries risk variables}

Poor oral hygiene $(p=0.02)$ and high counts of salivary lactobacilli $(p=0.001)$ were found in children with $\mathrm{CL} / \mathrm{P}$ compared to non-cleft controls. Ten-year-old children with $\mathrm{CL} / \mathrm{P}$ had lower stimulated saliva secretion rate compared to non-cleft controls but this difference was not significant. Saliva secretion rate for the 5-year-olds was considered non-reliable and was not included. No significant difference were found between children with CL/P and non-cleft controls regarding; counts of mutans streptococci in saliva, buffering capacity of saliva, fluoride exposure and intake frequency per day.

\section{Caries risk profiles}

The average Cariogram sectors for children with CL/P and non-cleft controls are shown in Figure 10. There were no significant differences in the average chance to avoid caries between children with CL/P and non-cleft controls. The estimated average chance to avoid caries ranged from 59 to $67 \%$. However as seen in Table 5, the odds for being categorized with high caries risk in $\mathrm{CL} / \mathrm{P}$ children was significantly elevated $(\mathrm{OR}=1.89 ; 95 \% \mathrm{Cl}=1.25-$ 2.86). In Table 6 the caries frequency in the high and low risk categories are presented. As a result, children within the high risk group have a clear tendency to have increased caries frequency. However, not statistical significant. 
Figure 10. The average caries risk factors analyzed with Cariogram.

Chance of avoiding caries

aiet

Bacteria

- Susceptibility

- Circumstances
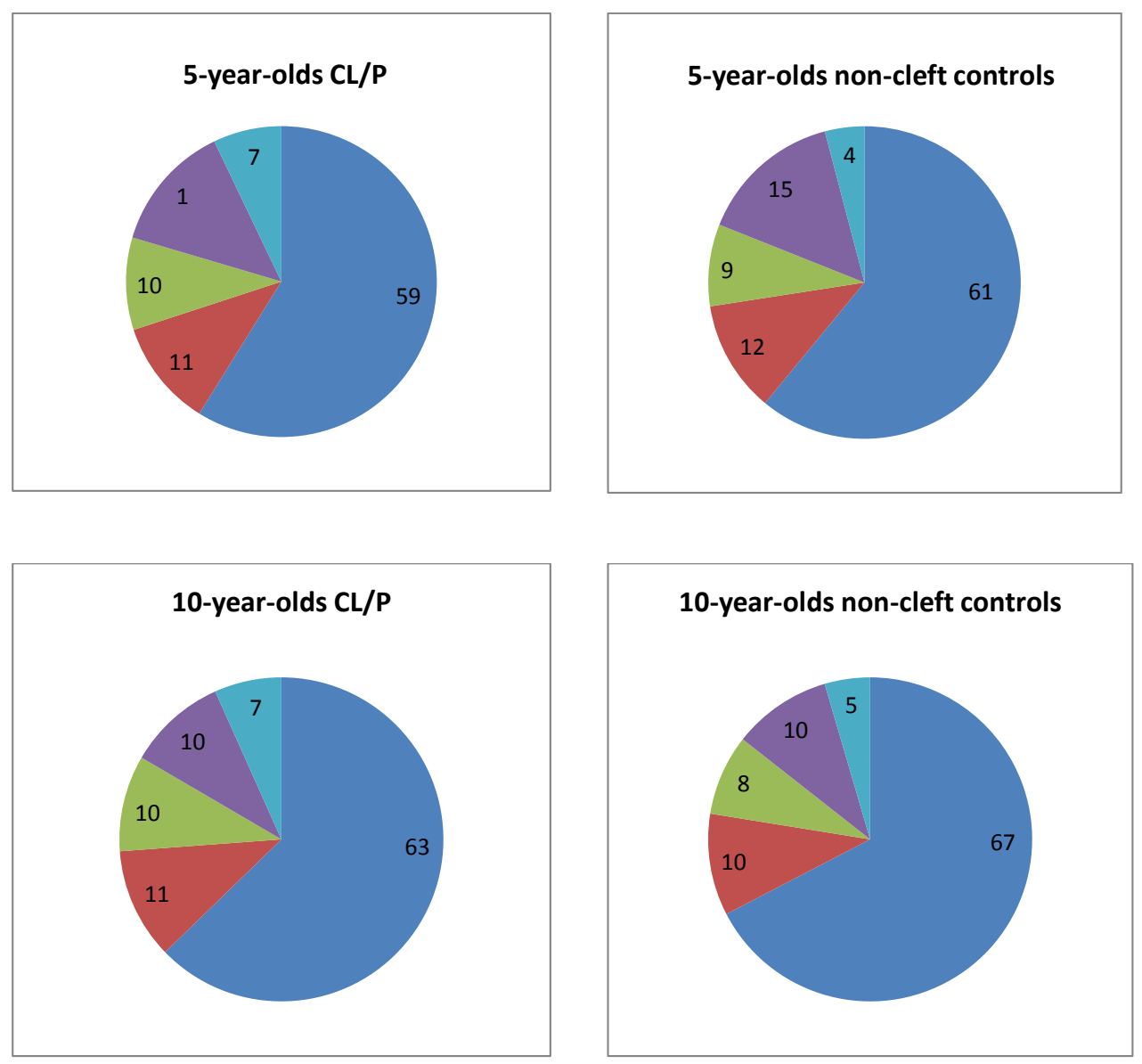


\begin{tabular}{lrcccc}
\hline Groups & $\mathrm{n}$ & Risk $^{\mathrm{a}}$ & Low risk $^{\mathrm{b}}$ & OR & 95\% Cl \\
\hline Total material & & & & & \\
CL/P & 133 & 71 & 62 & 1.89 & $1.25-2.86$ \\
Non-cleft controls & 297 & 112 & 185 & & \\
\hline 5-year-olds & & & & & \\
CL/P & 77 & 46 & 31 & 1.65 & $0.94-2.91$ \\
Non-cleft controls & 133 & 63 & 70 & & \\
\hline 10-year-olds & & & & & \\
CL/P & 56 & 25 & 31 & 1.89 & $1.01-3.53$ \\
Non-cleft controls & 164 & 49 & 115 & & \\
\hline
\end{tabular}

Table 5. Distribution of children with increased caries risk versus low risk in the two groups assessed with the Cariogram model. The values denote the number of subjects.

${ }^{a} 0-60 \%$ chance to avoid caries; ${ }^{b} 61-100 \%$ chance to avoid caries.

\begin{tabular}{lll}
\hline Groups & Risk $^{\mathrm{a}}$ & Low risk $^{\mathrm{b}}$ \\
\hline 5-year-olds & & \\
$\begin{array}{l}\text { Children with CL/P } \\
\text { dmfs 1-6 (SD) }\end{array}$ & $1.4(2.9)$ & $0.9(2.1)$ \\
dmfs 3-6 (SD) & $1.2(2.5)$ & $0.8(2.1)$ \\
Non-cleft controls & & $0.6(2.5)$ \\
dmfs 1-6 (SD) & $1.2(3.5)$ & $0.5(1.8)$ \\
dmfs 3-6 (SD) & $1.0(3.0)$ & \\
\hline 10-year-olds & & $1.2(1.8)$ \\
Children with CL/P & & $1.1(1.8)$ \\
dmfs 1-6 + DMFS 1-6 (SD) & $1.8(2.5)$ & \\
dmfs 3-6 + DMFS 3-6 (SD) & $1.6(2.3)$ & $1.0(2.3)$ \\
Non-cleft controls & & $0.9(2.2)$ \\
dmfs 1-6 + DMFS 1-6 & $3.5(4.5)$ & \\
dmfs 3-6 + DMFS 3-6 & $3.2(4.1)$ & \\
\hline
\end{tabular}

Table 6. Caries frequency (mean and SD) in relation to risk category.

${ }^{a} 0-60 \%$ chance to avoid caries; ${ }^{b} 61-100 \%$ chance to avoid caries. 


\section{Health-related quality of life}

The general HRQoL overall mean T-value for 5-year-old children was $55.3(\mathrm{SD} \pm 5.1$ ) versus $57.0(\mathrm{SD} \pm 6.4)$ for the 10 -year-old children. There were no significant differences between children with $\mathrm{CL} / \mathrm{P}$ and non-cleft controls. There was however an individual difference in $\mathrm{T}$-values between different dimensions. The T-values range span was 3-74 and with a skewness of rating higher HRQoL. Out of the 442 participants, $9 \%$ had missing information on one or more single KIDSCREEN items.

\section{HRQoL in 5-year-old children}

Proxy-rated HRQoL in children did not differ significantly in any dimension between children with CL/P and non-cleft controls (Figure 11a). For standard deviation see Paper III. No difference in HRQoL between children with a visible cleft $(\mathrm{CL} \pm \mathrm{P})$ and children with a nonvisible cleft (CP) could be found. However, girls with CL/P had significantly higher scores in "moods and emotions" in comparisons to the boys with $\mathrm{CL} / \mathrm{P}(\mathrm{p}=0.02)$. When children adopted from China and the rest of the children with $\mathrm{CL} / \mathrm{P}$ were compared, significant difference were seen in the dimensions, "moods and emotions" $(p<0.00)$, "parent relation and home life" ( $p<0.00)$, and "social support and peers" $(p=0.02)$.

\section{HRQoL in 10-year-old children}

Self-rated HRQoL in children did not differ significantly in any dimension between the two groups. There was a tendency toward a lower score in "social support and peers" in children with CL/P compared with non-cleft controls. No difference was found in HRQoL between children with a visible cleft $(\mathrm{CL} \pm \mathrm{P})$ and children with a non-visible cleft $(\mathrm{CP})$. Additionally, no gender difference in HRQoL could be found, (Figure 11b). For standard deviation see Paper III. In this age group the number of adoptees (10) was insufficient for calculating differences between adopted and rest of the children with CL/P. 
Figure 11a-b. T-mean values for children with $C L / P$ and non-cleft controls. Values are given as mean. No significant differences were found. Norm score is 50, marked as a horizontally black line, and standard deviation is 10, KIDSCREEN-52 (Ravens-Sieberer et al. 2006).

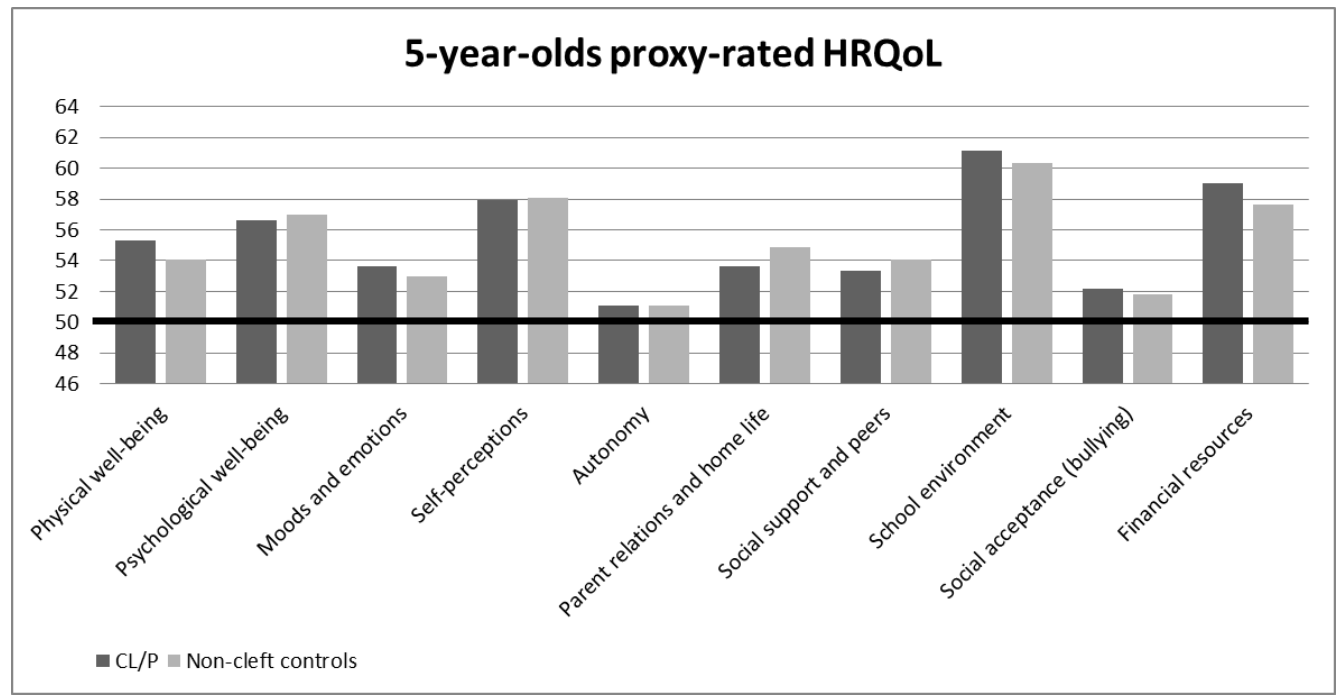

11a. HRQoL in 5-year-old children.

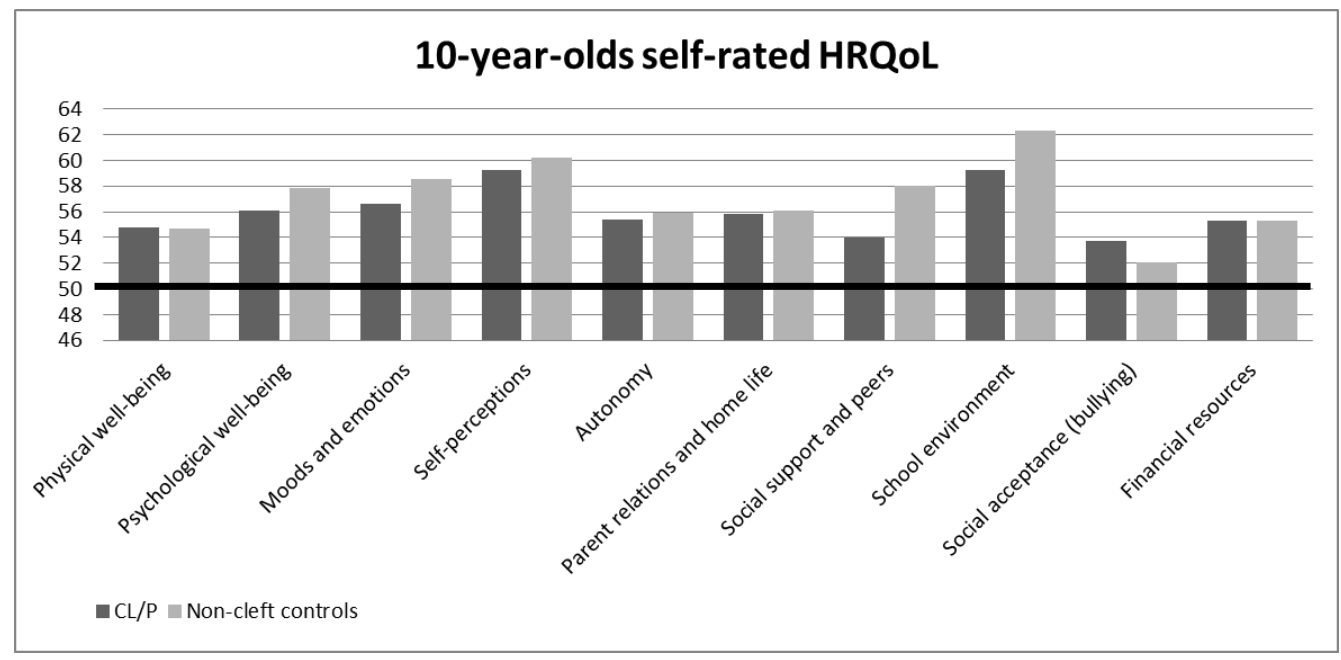

11b. HRQoL in 10-year-old children. 


\section{HRQOL and dental caries}

HRQoL did not differ significantly between children with presence or absence of caries. Caries frequency did not correlate to HRQoL in any dimension or in overall T-values. The same results were seen when children with $\mathrm{CL} / \mathrm{P}$ and non-cleft controls were analysed separately.

\section{Stress response}

Short time interval ( $<60 \mathrm{~min}$ ) between waking up and cortisol sampling, may result in a risk of a modifying cortisol arousal reaction (CAR). Since that would give false high cortisol concentrations, we excluded 46 saliva samples from the first morning (19, 5-year-olds) and $44,(23,5$-year-olds) from the second morning sampling in the tables and from the statistical analysis.

There was a normal diurnal cortisol rhythm and a good correlation between morning cortisol concentrations on day 1 and day $2(\mathrm{R}-\mathrm{level}=0.44)($ Figure 12a-b) and no significant difference between days (Wilcoxon's signed rank test).

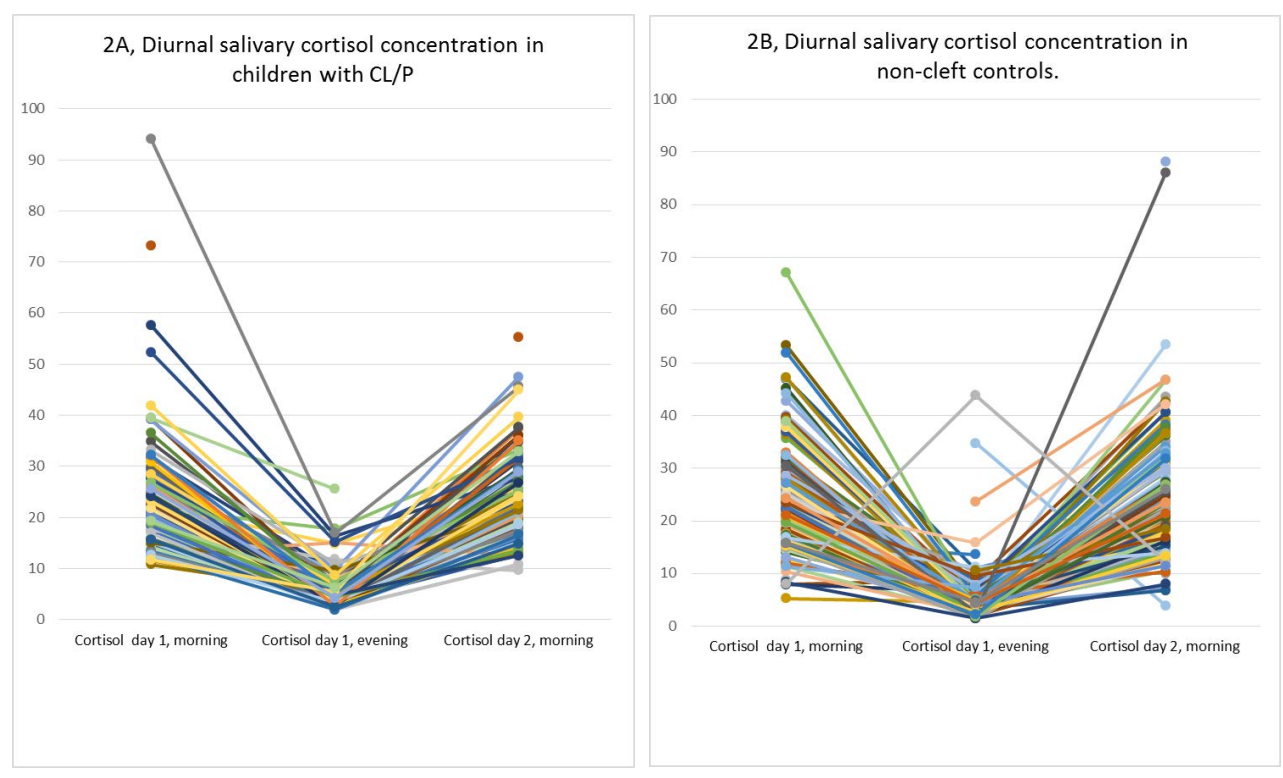

Figure 12.Diurnal cortisol concentration in saliva.

We found no association between salivary cortisol concentration and birthplace. There was no difference in the concentration of salivary cortisol between children with visible cleft $(C L \pm P)$ and non-visible cleft $(\mathrm{CP})$ and the concentration of salivary cortisol did not differ between 
type of cleft. Therefore, all results are presented as comparisons of all CL/P children and noncleft controls.

There was no significant difference in cortisol concentration, $\mathrm{AUC}_{\mathrm{G}}, \mathrm{AUC}_{1}$ and cortisol secretion decline when comparing all children (5- and 10-year-olds, girls and boys) with CL/P and non-cleft controls and no difference when comparing all girls with all boys (both children with CL/P and non-cleft controls). No difference was registered in cortisol concentration between all 5-year-old children (boys and girls with or without CL/P) and all 10-year-olds, and no difference between 5-year-olds and 10-year-olds in children with CL/P or in non-cleft controls. In addition, there were no significant differences in the total secretion of salivary cortisol during daytime represented as the area under curve from ground $\left(\mathrm{AUC}_{\mathrm{G}}\right)$ and the increase of salivary cortisol secretion during daytime $\left(\mathrm{AUC}_{\mathrm{I}}\right)$ between children with $\mathrm{CL} / \mathrm{P}$ and non-cleft controls (Table 7) .

\begin{tabular}{|c|c|c|c|c|c|c|c|c|c|}
\hline & \multicolumn{3}{|c|}{ All } & \multicolumn{3}{|c|}{ Boys } & \multicolumn{3}{|c|}{ Girls } \\
\hline & $\mathrm{CL} / \mathrm{P}$ & $\begin{array}{l}\text { Non-cleft } \\
\text { controls }\end{array}$ & $\mathrm{p}$-value & $\mathrm{CL} / \mathrm{P}$ & $\begin{array}{l}\text { Non-cleft } \\
\text { controls }\end{array}$ & p-value & $\mathrm{CL} / \mathrm{P}$ & $\begin{array}{l}\text { Non-cleft } \\
\text { controls }\end{array}$ & $\mathrm{p}$-value \\
\hline${ }^{1} \mathrm{AUC}_{\mathrm{G}}$ & 153 & 139 & 0.95 & 149 & 131 & 0.84 & 155 & 148 & 0.91 \\
\hline${ }^{1} \mathrm{AUC}_{\mathrm{I}}$ & -103 & -93 & 0.37 & -101 & -82 & 0.26 & -105 & -97 & 0.90 \\
\hline $\mathrm{A} 1(\mathrm{nmol} / \mathrm{L})$ & $\begin{array}{c}22.4 \\
(18.0-28.4)\end{array}$ & $\begin{array}{c}23.2 \\
(17.4-29.1)\end{array}$ & 0.64 & $\begin{array}{c}21.8 \\
(17.8-28.0)\end{array}$ & $\begin{array}{c}23.4 \\
(17.2-30.0)\end{array}$ & 0.52 & $\begin{array}{c}23.3 \\
(18.4-32.0)\end{array}$ & $\begin{array}{c}23.2 \\
(17.6-29.1)\end{array}$ & 0.88 \\
\hline $\begin{array}{l}\text { Cortisol decline } \\
(\mathrm{nmol} / \mathrm{L})\end{array}$ & $\begin{array}{c}17.8 \\
(12.8-22.1)\end{array}$ & $\begin{array}{c}19.4 \\
(13.8-25.6)\end{array}$ & 0.22 & $\begin{array}{c}16.4 \\
(11.8-21.7)\end{array}$ & $\begin{array}{c}19.5 \\
(12.6-23.5)\end{array}$ & 0.27 & $\begin{array}{c}19.4 \\
(13.6-27.0)\end{array}$ & $\begin{array}{c}19.4 \\
(14.3-26.2)\end{array}$ & 0.82 \\
\hline N (AUCG, AUCI) & 64 & 131 & - & 31 & 62 & - & 33 & 69 & - \\
\hline $\mathrm{n}(\mathrm{A} 1)$ & 81 & 134 & - & 44 & 55 & - & 37 & 79 & - \\
\hline n (Cortisol decline) & 82 & 135 & - & 44 & 57 & - & 38 & 78 & - \\
\hline
\end{tabular}

Table 7. Daytime salivary cortisol secretion and decline presented as Area under curve from ground $\left(A U C_{G}\right)$ and Area under curve increase $\left(A U C_{I}\right)$ according to genders and cleft $(C L / P)$ or non-cleft controls. There were no significant differences between groups.

\section{Concentration of salivary cortisol 5-year-old children}

When considering all 5-year-old children (girls and boys) there was no difference in salivary cortisol between children with CL/P and non-cleft controls, or between genders in the study or control group (Table 8).

\section{Concentration of salivary cortisol 10-year-old children}

There was no significant difference in salivary cortisol between 10-year-old children (boys and girls) with CL/P and non-cleft controls, although the concentration of salivary cortisol at $8 \mathrm{pm}$ was significantly higher in boys with $\mathrm{CL} / \mathrm{P}$ (median 4.9, range 2.2-17.7) compared to non-cleft controls (median $3.3 \mathrm{nmol} / \mathrm{L}$, range1.8-43.8), $\mathrm{p}=0.006$ (Figure 13 and Table 8). There was no difference in salivary cortisol levels at $8 \mathrm{pm}$ in girls. 


\begin{tabular}{|c|c|c|c|c|c|}
\hline \multirow[t]{2}{*}{ Gender } & \multirow{2}{*}{$\begin{array}{l}\text { Time } \\
\text { points }\end{array}$} & \multicolumn{2}{|c|}{ 5-year-olds } & \multicolumn{2}{|c|}{ 10-year-olds } \\
\hline & & $\mathrm{CL} / \mathrm{P}$ & $\begin{array}{l}\text { Non-cleft } \\
\text { controls }\end{array}$ & $\mathrm{CL} / \mathrm{P}$ & $\begin{array}{l}\text { Non-cleft } \\
\text { controls }\end{array}$ \\
\hline \multirow{6}{*}{$\begin{array}{l}\text { Boys and } \\
\text { girls }\end{array}$} & Day 1 & (42) & $(58)$ & (39) & (73) \\
\hline & $8 \mathrm{am}$ & $23.2 ; 10.8-94.1$ & $23.3 ; 8.0-53.3$ & $21.2 ; 12.9-39.2$ & $22.7 ; 5.3-67.1$ \\
\hline & Day 1 & $(46)$ & (73) & (44) & $(100)$ \\
\hline & $8 \mathrm{pm}$ & $4.5 ; 1.9-25.5$ & $4.0 ; 1.5-13.6$ & $4.8 ; 2.0-17.7$ & $3.8 ; 1.4-43.8$ \\
\hline & Day 2 & (41) & $(55)$ & (39) & $(76)$ \\
\hline & $8 \mathrm{am}$ & $22.6 ; 10.7-55.3$ & $22.2 ; 7.4-86.0$ & $25.2 ; 9.6-47.5$ & $20.9 ; 3.9-88.1$ \\
\hline \multirow[t]{6}{*}{ Boys } & Day 1 & (23) & (31) & (21) & (21) \\
\hline & $8 \mathrm{am}$ & $21.7 ; 10.8 ; 39.5$ & $23.8 ; 15.6-42.8$ & $21.8 ; 12.9-39.2$ & $22.8 ; 8.1-67.1$ \\
\hline & Day 1 & (24) & (40) & (24) & (35) \\
\hline & $8 \mathrm{pm}$ & $4.3 ; 2.1-25.5$ & $4.4 ; 2.4-13.6$ & $4.9 ; 2.2-17.7$ & $3.3 ; 1.8-43.8$ \\
\hline & Day 2 & (19) & (28) & (21) & (27) \\
\hline & $8 \mathrm{am}$ & $21.7 ; 10.7-44.9$ & $23.8 ; 7.4-86.0$ & $25.2 ; 9.6-47.5$ & $18.5 ; 3.9-88.1$ \\
\hline \multirow[t]{6}{*}{ Girls } & Day 1 & (19) & (27) & (18) & (52) \\
\hline & $8 \mathrm{am}$ & $25.4 ; 12.6-94.1$ & $27.0 ; 23.3-53.3$ & $20.6 ; 14.1-34.8$ & $22.7 ; 5.3-44.2$ \\
\hline & Day 1 & (22) & (33) & $(20)$ & (65) \\
\hline & $8 \mathrm{pm}$ & $4.7,1.9-16.9$ & $3.7 ; 1.5-8.7$ & $4.6 ; 2.0-7.3$ & $4.1 ; 1.4-23.7$ \\
\hline & Day 2 & (22) & (27) & (18) & (49) \\
\hline & $8 \mathrm{am}$ & $25.6 ; 10.9-55.3$ & $21.6 ; 11.6-53.4$ & $25.6 ; 14.7-37.6$ & $23.0 ; 8.0-46.8$ \\
\hline
\end{tabular}

Table 8. Diurnal salivary cortisol concentrations (nmol/L) in all 271 children split by age, sex and diagnosis. Diurnal salivary cortisol concentrations in all children split by age, sex and diagnosis. Values are given as (n), median, minimum and maximum.
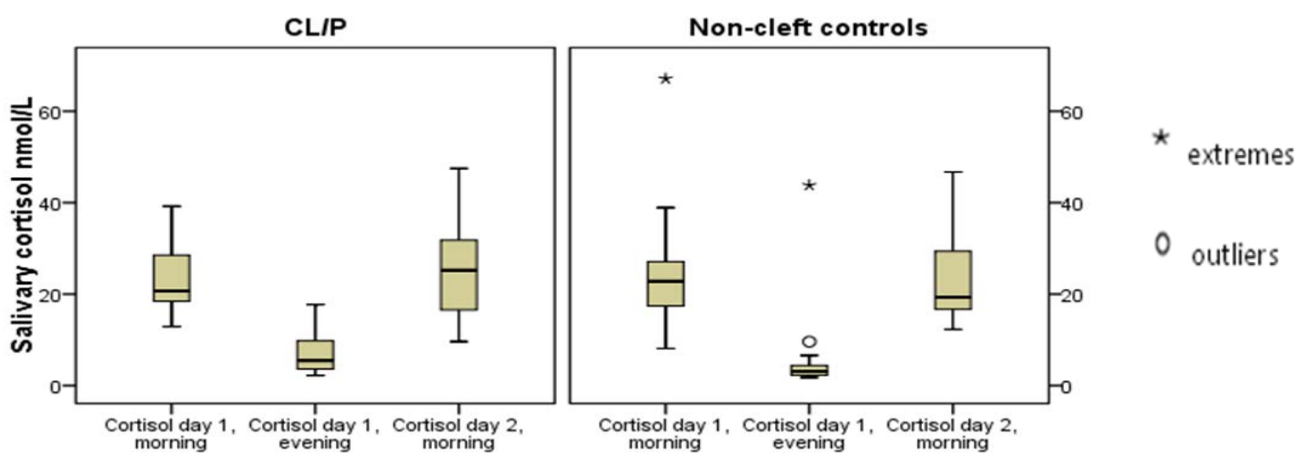

Figure 13. Comparison of salivary cortisol concentrations in 10-year-old boys with CL/P and non-cleft controls. There was a significant difference in the evening, $n=24 / 35, P=0.006$. 
Correlation between concentration of salivary cortisol, age, gender and HRQLL

Age and gender showed no correlation with salivary cortisol concentration either for morning or evening saliva samples. The concentration of cortisol in the evening was correlated with $\mathrm{CL} / \mathrm{P}$ in all children (Spearman's rho, $\mathrm{n}=267,0.16, \mathrm{p}=0.01$ ) and in 10-year-olds (Spearman's rho, $n=144,0.18, p=0.03$ ), but not in 5-year-olds. The concentration of salivary cortisol was not correlated with HRQoL in any dimensions or in overall T-values in either age group.

Multiple linear regression analysis adjusted for age and gender showed an interaction in 5 -year-old children between evening salivary cortisol concentration and the HRQoL dimension "school environment" (adjusted R square 0.05, $\mathrm{n}=113$, $\mathrm{p}$-value $=0.040$ ). After adjustment for mass significance using the Bonferroni method this interaction was not significant $(\mathrm{p}=0.40)$.

\section{Stress response and dental caries}

No significant differences were seen between children with caries or absence of caries and concentration of cortisol in saliva at no time point, cortisol secretion decline, $\mathrm{AUC}_{\mathrm{G}}$ or $\mathrm{AUC}_{\mathrm{I}}$. Neither when 5- and 10-year-old children were analysed together nor when 5-year-olds and 10 -year-olds were analysed separately. No difference was seen when children with CL/P and non-cleft controls were analysed separately.

There was a weak negative correlation in caries frequency and evening salivary cortisol concentration in all 10-year-old children, girls and boys with $\mathrm{CL} / \mathrm{P}$ and non-cleft controls (Spearman's rho, $\mathrm{n}=142,-, 19, \mathrm{p}=0.02$ ), and also in non-cleft children (Spearman's rho, $\mathrm{n}=100,-, 28, \mathrm{p}=0.005)$. No other correlations were seen between caries frequency and salivary cortisol concentration. No correlation was seen in caries frequency and cortisol decline, $\mathrm{AUC}_{\mathrm{G}}$ or $\mathrm{AUC}_{\mathrm{I}}$. 


\section{Discussion}

This thesis has focused on 5- and 10-year-old children with CL/P and their caries prevalence and frequency, caries risk, enamel defects prevalence and frequency, HRQoL and stress response in comparison to non-cleft children in the same ages.

The main findings were that 5-year-old children with $\mathrm{CL} / \mathrm{P}$ had higher caries prevalence and frequency than their peers. Caries risk was elevated in children with CL/P maybe because children with $\mathrm{CL} / \mathrm{P}$ had less good oral hygiene and higher counts of lactobacilli.

Furthermore, HRQoL was similar in children with $\mathrm{CL} / \mathrm{P}$ and non-cleft controls and comparable to a European norm population. Children with $\mathrm{CL} / \mathrm{P}$ were not more stressed than their non-cleft controls as measured with cortisol concentration in saliva. Their general life situations were well adjusted, although the older children with CL/P felt more excluded and less supported by peers.

\section{Dental caries prevalence and frequency}

5-year-old children with $\mathrm{CL} / \mathrm{P}$ had significantly more caries than the non-cleft controls while this was not the case in the mixed dentition of the 10-year-olds. However, when the two age groups were analyzed together the caries prevalence was $41 \%$ in children with $\mathrm{CL} / \mathrm{P}$ compared to $29 \%$ in the non-cleft controls group. The results were in agreement with several previous studies (Antonarakis, Palaska et al. 2013, King, Wong et al. 2013, Kirchberg, Makuch et al. 2014) but in contrast to others (Lucas, Gupta et al. 2000, Hasslöf and Twetman 2007, Jindal et al. 2011). Earlier data suggest that children with cleft lip and palate (CLP) have more caries than children with isolated cleft lip (CL) (Bian, Du et al. 2001, Chapple and Nunn 2001, Besseling and Dubois 2004) but this could not be verified in the present study. Five-year-old children with $\mathrm{CL} / \mathrm{P}$ had more caries in the primary teeth than the 10 -year-olds. This was likely explained by the high number of exfoliated caries-affected anterior teeth in the older age group.

The finding that the children with $\mathrm{CL} / \mathrm{P}$ did not have a higher caries prevalence or frequency in their permanent teeth in comparison to non-cleft controls was comforting and inspiring, being a result of regular and comprehensive preventive care. Otherwise, it is well established that high caries levels in the primary dentition are related to an increased caries risk in the permanent dentition (Isaksson, Alm et al. 2013, Mejáre, Axelsson et al. 2014). Caries treatment in young ages can furthermore cause dental fear and behavior management problems (Raadal, Strand et al. 2002). This can jeopardies orthodontic treatment frequently needed in CL/P children. In any case, our present findings reinforce the fact that preventive care should be introduced in pediatric and dental healthcare at an early age and a pediatric dentist responsible for oral health should be included in the cleft team. 


\section{Developmental enamel defects prevalence and frequency}

Enamel defects are common in individuals with $\mathrm{CL} / \mathrm{P}$ but also in non-cleft controls. In this study the prevalence of enamel defects was $26 \%$ in primary teeth in non-cleft controls and $47 \%$ in permanent teeth. This is in the same magnitude as in other studies reporting $24-29 \%$ prevalence of enamel developmental defects in primary teeth (Li, Navia et al. 1995, Lunardelli and Peres 2005, Corrêa-Faria, Martins-Junior et al. 2013) and 49-63\% in permanent teeth (Dummer, Kingdon et al. 1990, Clarkson and O'Mullane 1992, Montero, Douglass et al. 2003).

Children with CL/P had high prevalence of enamel defects with permanent teeth more affected than primary teeth. The most common type was enamel hypomineralization on permanent anterior teeth, which was in accordance with previous reports (Chapple and Nunn 2001, Maciel, Costa et al. 2005, Gomes, Neves et al. 2009). The high prevalence of hypomineralization and hypoplasia in anterior permanent teeth may be an esthetical concern and also one of many risk factors for caries development in children with CL/P (Oliveira, Chaves et al. 2006, Targino, Rosenblatt et al. 2011, Vargas-Ferreira, Salas et al. 2015). A possible explanation why less enamel defects were seen in primary anterior teeth compared to permanent teeth in this study could be the high proportion of caries lesions.

\section{Dental caries risk}

A significantly higher proportion of children with $\mathrm{CL} / \mathrm{P}$ displayed increased caries risk. The background variables that differed between the two study groups were oral hygiene and salivary lactobacilli counts. The fact that oral hygiene may be jeopardized and impaired in children with CL/P has been suggested in many previous studies (Dahllöf, Ussisoo-Joandi et al. 1989, Wong and King 1998, Chopra, Lakhanpal et al. 2014). This can be a result of fear of brushing around the cleft area, the anatomy of the cleft or a loss of elasticity in the surgically repaired lip (Dahllöf, Ussisoo-Joandi et al. 1989). Other reasons can be restricted access for tooth brushing and natural cleaning since limited dental arch space attributed to the underdeveloped maxilla and higher incidence of supernumerary teeth causing malalignment of the teeth (Johnsen and Dixon 1984). There are also earlier reports that the levels of cariesassociated bacteria may be elevated in children with clefts (Bokhout, van Loveren et al. 1996, Ahluwalia, Brailsford et al. 2004). No increased count of mutans streptococci was found in children with $\mathrm{CL} / \mathrm{P}$, but more children with $\mathrm{CL} / \mathrm{P}$ than non-cleft controls displayed high and medium counts of salivary lactobacilli. The reason for this is not clear but impaired circumoral soft tissue movements in children with clefts (Rose, Staats et al. 2002) can prolong oral clearance time and favor growth of aciduric bacteria (Ahluwalia, Brailsford et al. 2004). Furthermore, untreated and open caries lesions are associated with increased lactobacilli counts (Shklair, Englander et al. 1956). The frequent occurrence of enamel defects (hypoplasia and hypomineralization) can also serve as retention for biofilm and may contribute to the elevated counts of salivary lactobacilli. 
The findings of the present study reinforce the assumption that children with CL/P may be regarded as caries risk patients on a group level but an individual risk assessment is needed to tailor and target the need of preventive action. A structured risk assessment model, should be included in the toolbox of the multi-professional team involved in the comprehensive care of $\mathrm{CL} / \mathrm{P}$ children.

As expected the group of children with immigrant status had significantly higher caries prevalence compared to Swedish natives. This was also true when caries frequency was compared. Our result was in accordance with previous studies from Sweden (Bankel, Eriksson et al. 2006, Jacobsson, Koch et al. 2011, Stecksén-Blicks, Hasslöf et al. 2014) and other Scandinavian countries (Skeie, Riordan et al. 2006, Christensen, Twetman et al. 2010). The number of children with CL/P and immigrant background $(n=9)$ was too small and therefore suboptimal for looking at differences in caries prevalence/frequency and birthplace.

\section{Health-related quality of life}

In 5- and 10-year-old children there were no differences in HRQoL, measured with KIDSCREEN-52, between children with CL/P and non-cleft controls. Our results confirmed findings in earlier studies that children with $\mathrm{CL} / \mathrm{P}$ have as good and similar HRQoL as children without a cleft (Sagheri, Ravens-Sieberer et al. 2009, Tannure, Soares et al. 2013, Feragen and Stock 2014). Individuals with CL/P are well adjusted and able to cope with the special challenges they encounter living with a cleft (Marcusson, Paulin et al. 2002, Locker, Jokovic et al. 2005, Stock, Feragen et al. 2015).

As a group, all children in this study had similar HRQoL compared to children in the general European population in all dimensions (Ravens-Sieberer, Gosch et al. 2006, Ravens-Sieberer, Herdman et al. 2014). The participating 10-year-old children in this study seemed to have even better HRQoL with overall mean T-value at 57.0, compared with 52.4 in 11-12-year-old schoolchildren in the study of Svedberg et al. (2013) using the same KIDSCREEN-52 questionnaire.

Ten-year-old children with CL/P perceive their HRQoL lower, in the dimension "social support and peers" than non-cleft controls. This can be interpreted as children with a CL/P feel less acceptance and support by peers, have less ability to form and maintain relationships, are less respected by peers and friends, have less experiences of positive group feeling, and feel less a part of a group than non-cleft controls (Ravens-Sieberer, Gosch et al. 2006). Facial appearance, acceptance by peers, and the desire to be like everyone else are important to preadolescents (Damiano, Tyler et al. 2007, Chetpakdeechit, Hallberg et al. 2009, Havstam, Laakso et al. 2011). Questions and negative comments from other children may have the result in that children with CL/P are feeling different (Havstam, Laakso et al. 2011). Furthermore, the frequent hypernasal speech in children with a cleft palate (Nyberg, Peterson et al. 2014) and aberrant facial appearance in children with $C L \pm P$ can be perceived negatively by other children (Blood and Hyman 1977, Hunt, Burden et al. 2006). In addition, peers to 
10-year-old children with CLP have concerns about the risk of teasing and bullying and how children with impaired speech might experience their situation (Nyberg and Havstam 2016).

As expected, social competence and aesthetic physical outcomes and appearance are more essential in 10-year-old children compared to 5-year-olds with CL/P. Previous studies measuring oral health-related quality of life (OHRQoL) have shown that children with cleft perceive their HRQoL in social-emotional well-being lower than controls (Ward, Vig et al. 2013, Kortelainen, Tolvanen et al. 2016) and this is in accordance with the result of this study. There was no difference between the HRQoL dimension "social support and peers" in 5-yearold children with CL/P compared to non-cleft controls. Maybe, this could be explained by the fact that HRQoL questionnaire were answered by the children's parents and not by the children themselves, such as in the 10-year-olds. Another explanation can be the younger age itself. During early childhood children with CL/P are not aware that they are unlike other children, having a congenital malformation causing aberrations in facial appearance and /or speech deviations (Chetpakdeechit, Hallberg et al. 2009). Later in childhood they become aware of the cleft and feel dissimilar due to their appearance, speech impairment, and that they are different because they need multiple and sometimes extensive medical and dental treatments (Chetpakdeechit, Hallberg et al. 2009). This is in agreement with the results of this study. However, lower scores in the dimension "social support and peers" in 10-year-old children with $\mathrm{CL} / \mathrm{P}$ was not statistically significant but it could be of clinical importance.

No difference in HRQoL between children with visible cleft (CL $\pm \mathrm{P})$ and children with nonvisible cleft (CP) was found. This is in agreement with an earlier study by Feragen et al. (2015) showing that $\mathrm{CL} \pm \mathrm{P}$ is not a risk factor for psychological problems but a risk factor for dissatisfaction with appearance. Marcusson et al. (2002) and Damiano et al. (2007) show that aesthetic concerns seems to be an important factor affecting HRQoL in adults and older children. The result of this study was not expected since it could be assumed that aesthetic physical appearance is more important in the society nowadays were social media, such as social networking sites and blogs, focusing on such things and are important parts in youngster's social daily life.

Other consequences are communications disabilities. Children with $\mathrm{CP}$ often have speech impairment (Nyberg, Peterson et al. 2014) and hearing impairment (Skuladottir, Sivertsen et al. 2015) that can affect their social competence due to their difficulties in communication with others. As well as with aesthetic concerns, also speech worries seem to influence HRQoL in children with CL/P (Damiano, Tyler et al. 2007). Since different difficulties occur in children with visible as well as non-visible clefts, no difference was detected between the two groups regarding HRQoL.

Five-year-old girls with CL/P scored higher in the dimension "moods and emotions" in comparison with boys. According to the KIDSCREEN handbook this can be interpreted as girls feel good and are in a good mood more often than boys (Ravens-Sieberer, Gosch et al. 2006). A similar gender difference in the subscale "emotional role" has been reported in 
adults by Mani et al. (2010) although there are also studies in children without gender differences (Millar, Bell et al. 2013, Tannure, Soares et al. 2013).

Proxy-rated HRQoL dimensions "moods and emotions", "parent relation and home life", and "social support and peers" was significantly lower in adopted children from China with CL/P compared to the rest of the children with $\mathrm{CL} / \mathrm{P}$. Lower score in the dimension "parent relation and home life" can be interpreted as adoptees with CL/P feel alone, overlooked, not appreciated, perceives parents as unavailable/unfair more often than the rest of the children with $\mathrm{CL} / \mathrm{P}$. Internationally adopted children may feel different not only because their different appearances, not having the same skin color and physical appearance, but also because of the fact that they are adopted. The adopted children may challenge difficulties in identify with parents and peers. These concerns seem to start already in 3-6-year-old children (Juffer and Tieman 2009). Adolescents adopted from other countries in young ages to Sweden seem to have good and comparable mental health to non-adopted adolescents (Cederblad, Hook et al. 1999). Family relations, various aspects of identity and peer relations explained much of the variance in mental health and self-esteem in the study by Cederblad et al. (1999).

It is optimistic that HRQoL did not differ between children with and without $\mathrm{CL} / \mathrm{P}$, despite the objective or perceived importance of social acceptance and aesthetic physical appearance in the society nowadays.

\section{HRQoL and dental caries}

There was no correlation between HRQoL and caries frequency and no statistically difference between children with presence or absence of caries. This is in agreement with Lee et al. (2010) showing no difference between 3-5-year-old Chinese caries-free and children with severe caries measuring HRQoL with PedsQL. Conversely, significant lower HRQoL measured with AUQUEI in 12-year-old Brazilian children with caries lesions compared to children without caries lesions has been reported (Paula, Meneghim et al. 2015). Additionally, in American 4-10-year-old children with CL/P lower HRQoL measured with PedsQL was correlated with higher caries frequency (Cook, Kerins et al. 2016).

The reason for not finding correlation or difference between HRQoL and caries in this study could be explained by the low caries frequency, as suggested by Oscarson et al. (2007). Studies including children with high caries frequency have shown correlation between lower HRQoL and caries (Paula, Meneghim et al. 2015, Cook, Kerins et al. 2016). Oscarson et al. (2007) concluded that caries incidence and prevalence is too low in Sweden to have major influence on young adults' perceived OHRQoL and well-being, despite lower overall OHRQoL between adolescents with high caries experience and no caries experience. Although caries experiences in Swedish children are too low to influence HRQoL at a group level it can be of importance in the individual child.

Unexpected, no correlation could be seen between caries frequency and the dimension "financial resources". Low socioeconomic status is often considered a risk factor for caries, 
but this was not obvious in this study. The reason for this is not clear. The dimension financial resources explores whether the child feels that he/she has enough financial resources to allow him/her to live a lifestyle which is comparable to other children and provides the opportunity to do things together with peers (Ravens-Sieberer, Gosch et al. 2006).

\section{Stress response}

The diurnal cortisol rhythms were normal in the performed analysis. The salivary cortisol concentrations were rather high in children with $\mathrm{CL} / \mathrm{P}$, but no higher than in the non-cleft controls. This was consistent with the results of Gassling et al. (2012) and Mueller et al. (2014) on salivary cortisol concentration in infants and adults with CL/P in comparison to non-cleft controls.

There were no differences in cortisol concentrations between 5- and 10-year-old children with $\mathrm{CL} / \mathrm{P}$ and non-cleft controls, nor when analyzing children with $\mathrm{CL} / \mathrm{P}$ and non-cleft controls separately. However, when adjusting for age there was a difference between genders. In 10 -year-old boys, but not in girls with CL/P the cortisol concentrations were higher in the evening than in the non-cleft controls. This difference in salivary cortisol concentration in the evening samples in the 10-year-old boys could be associated with the higher rate of behavioral problems during daytime in older boys with CL/P compared to non-cleft controls. The findings are in agreement with the results of a study by Collett et al. (2012). They found that 5- to 9-year-old boys with clefts have more behavioral problems categorized as internalizing, externalizing and total problems using the CBCL scale (Child Behavior Checklist scale) than non-cleft controls. These behavioral problems were worse in the older age groups ( 7 to 9 years). The authors suggest that stress associated with all the treatment procedures and the possible social stigmatization may be more important in the older age group when relations with peers become more important.

In this thesis no correlation was seen between perceived HRQoL and cortisol concentration. The results were consistent with those of da Silva et al. (2015), who found no correlation between quality of life measured using AUQUIE and diurnal decline in salivary cortisol in 12 -year-old children. However, other studies have reported conflicting results. Nickel et al. (2006) found reduction in the mean salivary cortisol concentrations and four dimensions of quality of life measured using SF-36 (vitality, social functioning, role limitations due to emotional problems in mental health, mental health) in adolescent boys with bullying behavior before and after treatment with family therapy interventions. The authors suggest "that there is a dose relation between cortisol secretion and mental health in adolescents".

The long-term effects of CL/P on mental health and salivary cortisol concentrations in this study group will need a second examination in adolescents and/or adulthood. However, previous studies in these age groups show that there is a similar positive long-term prognosis for HRQoL as that found in our 5-10-year-old children (Mani, Carlsson et al. 2010, Pisula, Lukowska et al. 2014). 
It is encouraging that children with $\mathrm{CL} / \mathrm{P}$ in this thesis were not more stressed than the noncleft controls.

\section{Stress response and dental caries}

In this study no significant difference in cortisol concentration was found between caries-free children and children with one or more caries lesions. This is in accordance with Kambalimath et al. (2010) reporting no difference in salivary cortisol concentration between caries-free children and children with one or more caries lesions. In two other studies, comparing children with no clinical sign of caries to those with severe caries (more than five decayed teeth) significant difference was found (Rai, Hegde et al. 2010, Pani and Al Odhaib 2013). The reason for the conflicting result can possibly be explained by the low caries experience in the children with caries in this study and in the study by Kambalimath et al. (2010). However, in all 10-year-old children, also in non-cleft children, a week negative correlation in evening cortisol concentration in saliva and caries frequency was found, but no correlation between caries frequency and cortisol decline, $\mathrm{AUC}_{\mathrm{G}}$ and $\mathrm{AUC}_{\mathrm{I}}$. This is contradictory to Boyce et al. (2010) showing positive correlation between caries frequency and daytime cortisol concentration measured with area under the curve. Analogous result with Boyce et al. (2010), lower diurnal decline in salivary cortisol concentration in children with caries compared to caries-free children have been reported by Barbosa et al. (2012). The result of the present study has to be drawn with caution since the correlation is very week. 
Methodological considerations 


\section{Methodological considerations}

\section{Participants}

First of all, the high number of non-responders of invited children with $\mathrm{CL} / \mathrm{P}$ of about $50 \%$ is a limitation. The exact reasons for the low interest to participate are unknown but many children with $\mathrm{CL} / \mathrm{P}$ have a history of extensive and long-term treatment needs and one additional examination could possibly have been perceived as one too many. Perhaps parents and children with $\mathrm{CL} / \mathrm{P}$ do not have the energy, motivation, or interest to participate. The nonparticipating invited CL/P children had a slightly higher frequency (18.5\%) BCLP, compared to the group who agreed to participate $(16.5 \%)$. The difference was not statistically significant. Furthermore, the non-participating children's general and oral health is unknown.

We have no exact information about the participating children's medical background or syndrome diagnosis, since this was solely described by the parents. A few children with, for us unknown syndromes may have been included in this study, but are probably very few since syndromes are rare and syndromes including cleft diagnosis are even more uncommon (Sekhon, Ethunandan et al. 2011, Socialstyrelsen 2016). We excluded two children who could not collaborate to dental examination and both of them had a complex medical background, analogous with rare syndromes.

Moreover, 44 children (32\%) of the participating children with CL/P were adopted from China in young ages. Most of them had primary lip surgery performed before arrival to Sweden and most part of the adoptees had complete clefts (25 children UCLP and 13 BCLP), which is in accordance with Hansson et al. (2012) reporting that $80 \%$ of the adoptees from China with CL/P are operated when arriving to Sweden and have more often BCLP then the native population. Only two children in the non-cleft group were adopted, one from China and one from Russia. This may influence the result but when comparing caries prevalence and frequency between children with CL/P adopted from China and the rest of the children with $\mathrm{CL} / \mathrm{P}$ no difference was found. Neither, there were no differences seen in the concentration of cortisol in saliva in morning and evening samples in adopted children with $\mathrm{CL} / \mathrm{P}$ and the rest of the children with CL/P. Although, there was a significant difference in 5-year-olds adopted from China versus the rest of children with CL/P in the HRQoL dimensions "moods and emotions", "parent relation and home life" and "social support and peers", without affecting the result for the total group of children with CL/P and non-cleft controls.

Medical or neuropsychiatric conditions were relatively common in the CL/P children. Neuropsychiatric conditions such as ADHD and autism have been shown to influence caries prevalence in groups of children with these diagnosis (Chandra, Anandakrishna et al. 2009, Blomqvist, Ahadi et al. 2011, El Khatib, El Tekeya et al. 2014) and HRQoL (Danckaerts, Sonuga-Barke et al. 2010, Kuhlthau, Orlich et al. 2010, Domellöf, Hedlund et al. 2014, Lee, Yang et al. 2016, Peasgood, Bhardwaj et al. 2016). Also asthma, congenital heart disease and 
diabetes can increase caries risk (Ponte, Tabaj et al. 2001, Stecksén-Blicks, Rydberg et al. 2004, Alavaikko, Jaakkola et al. 2011, Johnston and Vieira 2014, Sivertsen, Assmus et al. 2016) and impair HRQoL (Varni, Limbers et al. 2007, Chaplin, Hanas et al. 2009, Hanberger, Ludvigsson et al. 2009). Although the proportion of affected children was slightly higher in children with $\mathrm{CL} / \mathrm{P}$ than in the non-cleft controls this alone could not explain the difference in caries prevalence and frequency in 5-year-old children, or the differences in caries risk.

The non-cleft controls were recruited from six PDS clinics in the same geographic regions as the $\mathrm{CL} / \mathrm{P}$ children. Dental clinics with wide catchment area, both in small and large cities were chosen. The intention was to include children with both high and low socioeconomic backgrounds since this can influence their caries experiences, HRQoL and truly also their stress response. Dental assistants at the PDS clinics did call the children to their regular dental examination and at the same time asked them and their parents about participation in this study. No selection was done when the dental assistants were calling the children to examination. The parents and children who did not want to participate were unfortunately not listed. The drop-out rate for this group could therefore not be calculated. Consequently, the control group is a convenience sample. If the sample is representative for the whole population and generalizability of the results can be discussed.

\section{Dental caries and developmental enamel defects}

The limited attendance by children with CL/P made the study slightly underpowered, especially in 10-year-old children, which made any subgrouping on type of clefts or its location less meaningful.

No radiographs were taken and with visual-tactile caries detection only, the true caries prevalence is clearly underestimated. For example, in 5-year-old Swedish children, a "gain" of 1.2 proximal caries lesions was found for primary molars when bite-wings were added to the clinical examination (Anderson, Stecksén-Blicks et al. 2005). The use of bite-wings in caries surveys is controversial and should not be used unless the children clearly benefit from the examination, even though the radiation dosage is small if modern equipment and radiation protection is used. In this context, children with $\mathrm{CL} / \mathrm{P}$ are exposed to frequent radiographic examinations and this was the main reason to refrain from additional radiographs.

Nevertheless, the potential caries underscoring of proximal caries have to be considered. The underscoring is most likely of similar magnitude in both children with CL/P and non-cleft controls. But, if caries lesions are detected with visual tactile examination it is more likely that more caries lesions are present in proximal tooth surfaces. The caries frequency in children with caries is therefore probably underestimated.

Another limitation in this thesis is that enamel defects were not classified with an established index. If such an index has been used more accurate enamel defect prevalence and frequency could have been presented and more easily compared to earlier studies. 


\section{Dental caries risk variables and risk profiles}

Many of the 5-year-old children hesitated to cooperate with the stimulated saliva collection procedure. Several children found it difficult to hold the paraffin piece in the mouth and at the same time spit out the saliva. A few children chose to hold the paraffin in the hand when spitting out the saliva. For some of the 5-year-old children it was the first time chewing on a "chewing gum" and some of them disliked the taste. Furthermore, it seemed even more difficult for the children with CL/P to sample stimulated saliva. Therefore the secretion rate was considered non-reliable for the younger age group. True hyposalivation is relatively uncommon among preschool children (Sakeenabi and Hiremath 2011) so its influence on final Cariogram was likely limited. Moreover, an earlier study using Cariogram in schoolchildren have shown good validity despite omitted saliva secretion rates (Campus, Cagetti et al. 2009).

Unfortunately, we had no detailed information on dietary habits, entered in the diet Cariogram sector together with lactobacilli counts, to reflect the "sugar amount". Actually, this can have influenced this Cariogram sector and showing lower "sugar amount" than the real sugar consumption.

In the original Cariogram manual, five risk categories were advocated but in the clinicalpractical context, two risk categories, low risk versus some risk, are pertinent for the clinical decision-making and patient-centered prevention. This was the reason to merge the original moderate, high and very high categories and compare them with the low and very low risk categories, assuming that preventive "over-treatment" is somewhat more acceptable than neglecting professional preventive care to those with a true need.

The modification of the scores entered into the program was made to match the age groups and children living in Sweden and may not be relevant or applicable elsewhere. For example, according to a national survey, $60 \%$ of the 12 -year-old children were free from cavities $(\mathrm{DMFS}=0)$ (Nordenram 2012). Therefore, also early enamel lesions were considered in the algorithm "past caries history" in our study which was in contrast to the manual.

A limitation in caries risk assessment with Cariogram is that no indirect factors such as socioeconomic and immigrant background are included, only common risk factors immediately involved in the caries process.

\section{Health-related quality of life}

A generic HRQoL instrument, KIDSCREEN-52, was used and not a disease specific questionnaire or an OHRQoL instrument. The reason for choosing a generic instrument was our intention to compare HRQoL in children with CL/P and non-cleft controls. A disease specific instrument used for children with $\mathrm{CL} / \mathrm{P}$ was assumed to be uninterested and difficult for the non-cleft children and their caregivers to answer. The interpretation of the results from such a disease specific instrument was expected to be problematic for our purpose. In addition a disease specific instrument was not available when conducting this study. During the study 
period a specific HRQoL instrument for children with cleft are under development but not yet validated (Wong, Forrest et al. 2013). An OHRQoL instrument was not used because our intention was a broad problem approach and not only aspects of teeth, mouth, jaws and dental treatments impact on HRQoL. One of our aims was to compare HRQoL between children with visible cleft $(\mathrm{CL} \pm \mathrm{P})$ and invisible cleft $(\mathrm{CP})$. If available, a disease specific instrument may have been a better choice but only if this instrument also included general aspects of HRQoL. In children with CLP both aesthetic and communication consequences can affect HRQoL. A better approach to compare visible and invisible cleft might have been to compare children with cleft lip (CL) and cleft palate only (CP).

In HRQoL studies, physical dimensions are often better correlated between proxy raters and patients compared to psychosocial dimensions (Sneeuw, Sprangers et al. 2002). The psychosocial dimensions are only guesses from the proxies how the children/patients are feeling. The concrete and objective aspects are easier to answer for proxies, as the dimension physical well-being in KIDSCREEN-52. Comparisons of answers to KIDSCREEN-52 between children and parents have been performed and have shown an acceptable agreement between children and parents with item intraclass correlation coefficient (ICC) ranging from 0.45-0.62 (Ravens-Sieberer, Gosch et al. 2006). In HRQoL studies proxies tend to report more HRQoL problems than patients themselves, but the extent is often modest (Sneeuw, Sprangers et al. 2002). We can only speculate if parents to the 5-year-old children in this study reported more or less HRQoL problems in their children compared to the children themselves. However, the results in the 5-year-old groups must be understood as the parents' feelings of their children's satisfaction with life. This limits the possibility to exact compare results from the 5- and 10-year-old groups. But if you can't ask the children themselves you have to choose someone else.

Nine percent of the answered questionnaires had one or more single missing items and this was considered a small drop-out and has not influenced the results strongly.

The questionnaires were answered in varying places, in the dental clinic, in the examination room, in the waiting room or at home. This can interfere with the result but was hopefully of minor importance.

\section{Stress response}

There were fewer children with CL/P than non-cleft controls. However, the drop-out rates, of saliva samples for cortisol analysis, were lower in CL/P children (36\%) versus non-cleft controls (44\%), although the difference was not statistically significant. One explanation could be that parents of non-cleft controls have less motivation for and/or interest in collecting and returning samples of saliva compared to parents and children with CL/P.

Difficulties in saliva sampling in children with $\mathrm{CL} / \mathrm{P}$ due to impaired orofacial function and increased oral sensitivity can have influenced the saliva samplings. But no significant 
difference in stimulated saliva secretion between children with CL/P and non-cleft could be seen.

We have exact information about the time when the saliva samples were collected but no information on whether the sampling was performed on a weekday or on a weekend. Nor do we have any information about the children's sleep patterns on the nights before saliva collection. These aspects could interfere with the result but most likely to the same magnitude for children with CL/P and non-cleft controls.

Oral, written, and illustrative information was given on how to sample saliva but there are no guarantees that the caregivers adhered to the sampling instructions. The sampling time points and adherence to instructions not to eat, drink or brush teeth before sampling could have interfered with the results but likely to the same extent in both groups.

Saliva was collected three times on two consecutive days in order to measure the cortisol rhythm and analyze the interaction-feedback on the LHPA. By calculating the salivary cortisol decline from morning to evening, and AUC during daytime, we were able to estimate the mental stress response. The pattern of the diurnal rhythm could have been improved by multiple samplings on additional days. Our reason for collecting saliva samples only three times was to limit the burden on the children and their parents. We also thought that multiple sampling could interfere with their willingness to participate and compliance in the study due to the additional time required for sampling.

Unexpectedly, the cortisol concentration in this study was almost 50\% higher than in other studies with a similar study design using the same cortisol reagents and analyzed by the same biomedical assistant within the same laboratory (Törnhage 2002, Törnhage and Alfvén 2006, Wennström, Törnhage et al. 2011). The reasons for the higher cortisol concentration are not obvious. Cortisol concentrations showed the same distribution in both children with CL/P and non-cleft controls and the distribution were similar to those found in earlier studies, and there were no significant differences in morning cortisol concentrations between day 1 and day 2 . To eliminate false high morning cortisol concentrations due to cortisol arousal reactions, samples taken 20 to 60 minutes after waking up were excluded from all statistical analyses. If the rabbit antibodies in the batches of the commercial RIA method used in this study were more sensitive than antibodies used in earlier studies the evening cortisol concentration would also have been high and not normally low. Cortisol concentrations in the present study were also higher than in studies conducted in other countries, on the same age groups, with sampling of saliva at home and using immunoassay analysis (Davis, Bruce et al. 2002, Tomarken, Han et al. 2015). However, comparison of the results from different studies is complicated because of the use of differences in analytical methods, time points for saliva sampling, situations, and units of measurement. 
Ethical considerations 


\section{Ethical considerations}

The studies were approved by The Regional Ethical Review Board in Linköping, (Dnr 2011/252-31 and Dnr 2012/304-32). To conduct clinical studies involving patients all research should be performed in a way that it generates new useful knowledge. Our study is the first Swedish study since 1989 exploring caries frequency in children with CL/P and one of few studies worldwide studying caries risk factor in this group of children. Research of analyzing stress related hormone cortisol in saliva in correlation to HRQoL has not been presented earlier. Our intentions, to better understand oral health, HRQoL, and stress related factors in children with $\mathrm{CL} / \mathrm{P}$ was looked upon as a way in achieving our goal, improved oral and mental health in the future. This is in concordance to the most widely accepted human rights treaty, the United Nations convention on the rights of the child, article 24, health and health services: "States Parties recognize the right of the child to the enjoyment of the highest attainable standard of health and to facilities for the treatment of illness and rehabilitation of health. States Parties shall strive to ensure that no child is deprived of his or her right of access to such health care services."

The participating children in the study are young, $<11.8$ years of age, and have consequently weakened and/or reduced autonomy and are dependent on their caregivers. To consider the ethical principle, autonomy, respect for persons and the children's age, informed written consent for the children to participate was obtained from the caregivers for the children. However if a child did not agree to participate she/he was not included even if the caregivers have given written consent.

Parents to the children received a letter with information about the study and 10-year-old children also received written information adjusted to age. The letters included information about the purpose of the study, the voluntary participation, that they were free to discharge whenever they wanted and that data would be treated confidentially. Information was also given regarding questionnaires, clinical examinations, saliva samplings and that all participants, no matter if the children have $\mathrm{CL} / \mathrm{P}$ or not, would complete the same questionnaires, examinations and saliva samplings. If we have conducted the study today we would have included illustrative information, such as pictures and websites, adjusted to age for the 5-year-old children as well. The saliva samplings collected were registered in biobank 313, Skaraborg Hospital, Skövde and Biobank SoS 868, Ryhov Hospital, Jönköping.

Radiographic examinations were not included in the study. The use of intraoral bitewings radiography in caries surveys is controversial and should not be used unless the children clearly benefit from the examination. Many children in this study had good oral health and low caries risk and do not profit from such examination. 
If oral diseases were found during the examinations the children's ordinary dental clinic were informed. If mental health problems had emerged in connection to the questionnaire regarding health-related quality of life, we planned to offer the child referral to child and adolescent psychiatry, but this did not occur.

No financial support influenced the studies and the results. 


\section{Main findings and conclusions}

\section{Study I}

Preschool children with CL/P have more caries in the primary dentition than age-matched non-clefts controls. Enamel defects in both primary and early permanent dentition were more common in children with $\mathrm{CL} / \mathrm{P}$ compared to children without $\mathrm{CL} / \mathrm{P}$.

\section{Study II}

Children aged 5 and 10 years with $\mathrm{CL} / \mathrm{P}$ had higher caries risk, impaired oral hygiene and elevated salivary lactobacilli counts compared to children without CL/P.

\section{Study III}

Both 5- and 10-year-old Swedish children with CL/P had normal HRQoL compared to noncleft controls and to a European norm population. Children with CL/P were socially well accepted and their general life situations were well adjusted to their clefts.

\section{Study IV}

Children with CL/P had normal diurnal cortisol rhythm and were not more stressed than the non-cleft controls as measured with cortisol in saliva. 


\section{Clinical implications}

Dental caries is one of very few diseases that can be prevented. Children with CL/P need extensive medical and orthodontic treatment and should not have to experience any disease that can be prevented. Caries treatment in young ages can cause dental fear and behavior management problems and also medical fear. This together can jeopardize the treatment frequently needed in children with CL/P. Every effort to prevent caries in children with CL/P should be implemented and started already in young ages. Later, when primary teeth erupt, an objective and structured caries risk assessment should be applied, and if needed specialist paediatric dental care should be offered.

It is optimistic that HRQoL and stress response did not differ between children with $\mathrm{CL} / \mathrm{P}$ and non-cleft controls. In contrast, 10-year-old children with CL/P had feelings of more exclusion and less support or acceptance by peers and 10-year-old boys with CL/P had higher cortisol concentrations in the evening compared to non-cleft controls. According to the Swedish National treatment protocol all children with CL/P are followed up at the age of ten.

Questions about HRQoL containing peer relations are suggested to be included at this follow up, and if needed the child should be offered help to deal with these concerns. Educational information and personal contact with individuals with $\mathrm{CL} / \mathrm{P}$ for schoolmates to children with CLP has been shown to improve children's attitudes to CL/P (Blancher and Goodwyn 2016). 


\section{Ongoing and future perspectives}

Data for further studies, not included in the thesis, have been collected. The material will be used to compare children with CL/P and non-cleft controls concerning oral bacteria and salivary profiles, orofacial function measured with Nordic Orofacial Test - Screening (NOT-S), height, weight and body mass index (BMI) in general and in correlation to dental caries, and genetic difference in caries susceptibility.

Studies measuring orofacial function and oral sensibility in children with CL/P compared to non-cleft controls are sparse. Impaired circumoral soft tissue movements can prolong oral clearance time and favor the growth of aciduric bacteria and correspondingly caries development.

Weight and BMI in correlation to caries in children with CL/P in comparisons to non-cleft controls have not yet been published. Both high and low BMI have been reported to be associated with caries development. In addition studies analyzing BMI, length and weight in Swedish children with CL/P compared to non-cleft controls are sparse.

It is also important to follow up if any HRQoL changes arise when the children with CL/P get older. Moreover, with a combination of a generic HRQoL instrument and a disease specific instrument, it might be possible to look for differences between children with CL (visible cleft) and CP (non-visible cleft) in larger study groups.

Furthermore, also in in larger study groups, to look for differences in stress response between children with CL/P and non-cleft controls, as well as between different cleft diagnoses. In trying to increase the participation rate maybe cortisol analysis of hair, mailed in to laboratory, instead of saliva samplings at the dental clinic could be a better choice. 


\section{Acknowledgements}

I wish to express my sincere gratitude and appreciation to everyone who has inspired, supported, encouraged and made it possible for me to complete this thesis. My warm thanks to all of you. In particular, I also want to thank

All children and parents participating in the studies who so generously gave their time and effort to answer all my questions and collaborate to examinations and saliva samplings.

Agneta Marcusson my supervisor and co-author for inspiration to this thesis and for her enthusiasm and encouragement, for sharing experiences and expertise both in research and real life.

Christer Ullbro my co-supervisor, co-author and former head of Department of Paediatric Dentistry in Jönköping, for support and encouragement, giving me the opportunity to combine my clinical work with research, and all red markings in the manuscripts.

Svante Twetman my co-supervisor and co-author, for ideas, valuable advice, quick response, and for giving constructive feed-back.

Carl-Johan Törnhage my co-author for sharing his experiences and knowledge of stress response and for his genuine interest.

Anna-Karin Nilsson my co-author in paper I, for help in examine children included in the thesis.

Lucja Malko my dental assistant, for her diligence in contacting parents and children, warm friendship, and for her generous support.

Anne Rapp for friendship and understanding me in a special way since we are in the same "square".

Helén Janson for kind and never-ending help with practical matters, including India.

All my co-workers at the department of Paediatric Dentistry, The Institute for Postgraduate Dental Education in Jönköping for all your support and help.

Göran Koch for inspiring me to research.

Asa Zetterling, Gudrun Arén and Karin Hermansson for all assistance with references and endnote. 
The staffs at the dental clinics for letting me borrow their examination rooms and contacting parents and children.

My husband Peter and all my friends not always knowing what I was doing but noticed that this was important to me.

My father Lasse for giving me unconditional love, support and warm friendship.

My children Harald, Agnes and Sigrid for support and understanding when having an absent mother for some time and as well teaching me all I can about football, ice hockey and bandy. You are so important to me.

My dog Stella for reminding me to take necessary pauses from research and her never ending listening.

I also want to thank everyone I forgot to mention.

\section{Funding}

This study was supported by grants from FORSS - Medical Research Council of Southeast Sweden, Futurum, Academy of Health and Care Jönköping County Council, The Swedish Dental Association and The Swedish Society of Pediatric Dentistry. 
References 


\section{References}

Abramson JH. Survey methods in community medicine. 4 ed. Edinburgh: Churchill Livingstone; 1990.

Adam TC, Epel ES. Stress, eating and the reward system. Physiol Behav. 2007;91:449-58.

Ahluwalia M, Brailsford SR, Tarelli E, Gilbert SC, Clark DT, Barnard K, Beighton D. Dental caries, oral hygiene, and oral clearance in children with craniofacial disorders. J Dent Res. 2004;83:175-9.

Al-Dajani M. Comparison of dental caries prevalence in patients with cleft lip and/or palate and their sibling controls. Cleft Palate Craniofac J. 2009;46:529-31.

Al-Wahadni A, Alhaija EA, Al-Omari MA. Oral disease status of a sample of Jordanian people ages 10 to 28 with cleft lip and palate. Cleft Palate Craniofac J. 2005;42:3048.

Alavaikko S, Jaakkola MS, Tjaderhane L, Jaakkola JJ. Asthma and caries: a systematic review and meta-analysis. Am J Epidemiol. 2011;174:631-41.

Anderson M, Stecksén-Blicks C, Stenlund H, Ranggard L, Tsilingaridis G, Mejáre I. Detection of approximal caries in 5-year-old Swedish children. Caries Res. 2005;39:92-9.

Antonarakis GS, Palaska PK, Herzog G. Caries prevalence in non-syndromic patients with cleft lip and/or palate: a meta-analysis. Caries Res. 2013;47:406-13.

Bankel M, Eriksson UC, Robertson A, Köhler B. Caries and associated factors in a group of Swedish children 2- 3 years of age. Swed Dent J. 2006;30:137-46.

Barbosa TS, Castelo PM, Leme MS, Gaviao MB. Associations between oral health-related quality of life and emotional statuses in children and preadolescents. Oral Dis. 2012;18:639-47.

Bergström M, Modin B, Fransson E, Rajmil L, Berlin M, Gustafsson PA, Hjern A. Living in two homes-a Swedish national survey of wellbeing in 12 and 15 year olds with joint physical custody. BMC Public Health. 2013;13:868.

Berman AH, Liu B, Ullman S, Jadbäck I, Engström K. Children's Quality of Life Based on the KIDSCREEN-27: Child Self-Report, Parent Ratings and Child-Parent Agreement in a Swedish Random Population Sample. PLoS One. 2016;11:e0150545.

Besseling S, Dubois L. The prevalence of caries in children with a cleft lip and/or palate in Southern Vietnam. Cleft Palate Craniofac J. 2004;41:629-32.

Bian Z, Du M, Bedi R, Holt R, Jin H, Fan M. Caries experience and oral health behavior in Chinese children with cleft lip and/or palate. Pediatr Dent. 2001;23:431-4.

Blancher A, Goodwyn MA. The Effects of Age, Information, and Personal Contact on Attitudes Toward Individuals With Cleft-Lip and Palate. Cleft Palate Craniofac J. 2016;53:427-34.

Blomqvist M, Ahadi S, Fernell E, Ek U, Dahllöf G. Dental caries in adolescents with attention deficit hyperactivity disorder: a population-based follow-up study. Eur J Oral Sci. 2011;119:381-5. 
Blood GW, Hyman M. Children's perception of nasal resonance. J Speech Hear Disord. 1977;42:446-8.

Bokhout B, Hofman FX, van Limbeek J, Kramer GJ, Prahl-Andersen B. Increased caries prevalence in 2.5-year-old children with cleft lip and/or palate. Eur J Oral Sci. 1996a;104:518-22.

Bokhout B, van Loveren C, Hofman FX, Buijs JF, van Limbeek J, Prahl-Andersen B. Prevalence of Streptococcus mutans and lactobacilli in 18-month-old children with cleft lip and/or palate. Cleft Palate Craniofac J. 1996b;33:424-8.

Boyce WT, Den Besten PK, Stamperdahl J, Zhan L, Jiang Y, Adler NE, Featherstone JD. Social inequalities in childhood dental caries: the convergent roles of stress, bacteria and disadvantage. Soc Sci Med. 2010;71:1644-52.

Bratthall D, Hänsel Petersson G. Cariogram--a multifactorial risk assessment model for a multifactorial disease. Community Dent Oral Epidemiol. 2005;33:256-64.

Bratthall D, Hänsel Petersson G, Stjernswärd JR. Cariogram manual. Cariogram, Internet Version 2.01. 2004. [Available at:

www.mah.se/upload/FAKULTETER/OD/cariogram\%20program\%20caries/cariogma nual201net.pdf. Accessed June 8, 2011]

Brook AH. Multilevel complex interactions between genetic, epigenetic and environmental factors in the aetiology of anomalies of dental development. Arch Oral Biol. 2009;54 Suppl 1:S3-17.

Buzalaf MA, Pessan JP, Honorio HM, ten Cate JM. Mechanisms of action of fluoride for caries control. Monogr Oral Sci. 2011;22:97-114.

Bönecker M, Abanto J, Tello G, Oliveira LB. Impact of dental caries on preschool children's quality of life: an update. Braz Oral Res. 2012;26 Suppl 1:103-7.

Campus G, Cagetti MG, Sacco G, Benedetti G, Strohmenger L, Lingström P. Caries risk profiles in Sardinian schoolchildren using Cariogram. Acta Odontol Scand. 2009;67:146-52.

Campus G, Cagetti MG, Sale S, Carta G, Lingström P. Cariogram validity in schoolchildren: a two-year follow-up study. Caries Res. 2012;46:16-22.

Cederblad M, Hook B, Irhammar M, Mercke AM. Mental health in international adoptees as teenagers and young adults. An epidemiological study. J Child Psychol Psychiatry. 1999;40:1239-48.

Cedergren M, Källén B. Maternal obesity and the risk for orofacial clefts in the offspring. Cleft Palate Craniofac J. 2005;42:367-71.

Chandra P, Anandakrishna L, Ray P. Caries experience and oral hygiene status of children suffering from attention deficit hyperactivity disorder. J Clin Pediatr Dent. 2009;34:25-9.

Chaplin JE, Hanas R, Lind A, Tollig H, Wramner N, Lindblad B. Assessment of childhood diabetes-related quality-of-life in West Sweden. Acta Paediatr. 2009;98:361-6.

Chapple JR, Nunn JH. The oral health of children with clefts of the lip, palate, or both. Cleft Palate Craniofac J. 2001;38:525-8. 
Chetpakdeechit W, Hallberg U, Hagberg C, Mohlin B. Social life aspects of young adults with cleft lip and palate: grounded theory approach. Acta Odontol Scand. 2009;67:122-8.

Chopra A, Lakhanpal M, Rao NC, Gupta N, Vashisth S. Oral health in 4-6 years children with cleft lip/palate: a case control study. $N$ Am J Med Sci. 2014;6:266-9.

Christensen LB, Twetman S, Sundby A. Oral health in children and adolescents with different socio-cultural and socio-economic backgrounds. Acta Odontol Scand. 2010;68:34-42.

Cicchetti DV, Feinstein AR. High agreement but low kappa: II. Resolving the paradoxes. $J$ Clin Epidemiol. 1990;43:551-8.

Clarkson JJ, O'Mullane DM. Prevalence of enamel defects/fluorosis in fluoridated and nonfluoridated areas in Ireland. Community Dent Oral Epidemiol. 1992;20:196-9.

Coleman JR, Jr., Sykes JM. The embryology, classification, epidemiology, and genetics of facial clefting. Facial Plast Surg Clin North Am. 2001;9:1-13.

Collett BR, Cloonan YK, Speltz ML, Anderka M, Werler MM. Psychosocial functioning in children with and without orofacial clefts and their parents. Cleft Palate Craniofac J. 2012;49:397-405.

Cook AK, Kerins CA, Heppner CE. Dental Impacts on Health-related Quality of Life of Children with Orofacial Clefts. Pediatr Dent. 2016;38:218-23.

Corrêa-Faria P, Martins-Junior PA, Vieira-Andrade RG, Oliveira-Ferreira F, Marques LS, Ramos-Jorge ML. Developmental defects of enamel in primary teeth: prevalence and associated factors. Int J Paediatr Dent. 2013;23:173-9.

Corrêa-Faria P, Paixao-Goncalves S, Paiva SM, Martins-Junior PA, Vieira-Andrade RG, Marques LS, Ramos-Jorge ML. Dental caries, but not malocclusion or developmental defects, negatively impacts preschoolers' quality of life. Int J Paediatr Dent. 2016;26:211-9.

da Silva Pde L, Barbosa Tde S, Amato JN, Montes AB, Gaviao MB. Gingivitis, Psychological Factors and Quality of Life in Children. Oral Health Prev Dent. 2015;13:227-35.

Dahllöf G, Ussisoo-Joandi R, Ideberg M, Modéer T. Caries, gingivitis, and dental abnormalities in preschool children with cleft lip and/or palate. Cleft Palate J. 1989;26:233-7; discussion 7-8.

Damiano PC, Tyler MC, Romitti PA, Momany ET, Jones MP, Canady JW, Karnell MP, Murray JC. Health-related quality of life among preadolescent children with oral clefts: the mother's perspective. Pediatrics. 2007;120:e283-90.

Danckaerts M, Sonuga-Barke EJ, Banaschewski T, Buitelaar J, Dopfner M, Hollis C, Santosh P, Rothenberger A, Sergeant J, Steinhausen HC, et al. The quality of life of children with attention deficit/hyperactivity disorder: a systematic review. Eur Child Adolesc Psychiatry. 2010;19:83-105.

Dawes C. Salivary flow patterns and the health of hard and soft oral tissues. $J$ Am Dent Assoc. 2008;139 Suppl:18S-24S.

Davis EP, Bruce J, Gunnar MR. The anterior attention network: associations with temperament and neuroendocrine activity in 6-year-old children. Dev Psychobiol. 2002;40:43-56. 
Despars J, Peter C, Borghini A, Pierrehumbert B, Habersaat S, Muller-Nix C, Ansermet F, Hohlfeld J. Impact of a Cleft Lip and/or Palate on Maternal Stress and Attachment Representations. Cleft Palate Craniofac J. 2011;48:419-24.

Dixon DA. Defects of structure and formation of the teeth in persons with cleft palate and the effect of reparative surgery on the dental tissues. Oral Surg Oral Med Oral Pathol. 1968;25:435-46.

Domellöf E, Hedlund L, Ödman P. Health-related quality of life of children and adolescents with functional disabilities in a northern Swedish county. Qual Life Res.

2014;23:1877-82.

Dummer PM, Kingdon A, Kingdon R. Prevalence and distribution by tooth type and surface of developmental defects of dental enamel in a group of 15- to 16-year-old children in South Wales. Community Dent Health. 1990;7:369-77.

Ekbäck G, Persson C. Caries in five different socio-economic clusters in Orebro county. Community Dent Health. 2012;29:229-32.

El Khatib AA, El Tekeya MM, El Tantawi MA, Omar T. Oral health status and behaviours of children with Autism Spectrum Disorder: a case-control study. Int J Paediatr Dent. 2014;24:314-23.

Essex MJ, Klein MH, Cho E, Kalin NH. Maternal stress beginning in infancy may sensitize children to later stress exposure: effects on cortisol and behavior. Biol Psychiatry. 2002;52:776-84.

Essex MJ, Shirtcliff EA, Burk LR, Ruttle PL, Klein MH, Slattery MJ, Kalin NH, Armstrong JM. Influence of early life stress on later hypothalamic-pituitary-adrenal axis functioning and its covariation with mental health symptoms: a study of the allostatic process from childhood into adolescence. Dev Psychopathol. 2011;23:1039-58.

Feinstein AR, Cicchetti DV. High agreement but low kappa: I. The problems of two paradoxes. J Clin Epidemiol. 1990;43:543-9.

Fejerskov O. Concepts of dental caries and their consequences for understanding the disease. Community Dent Oral Epidemiol. 1997;25:5-12.

Fejerskov O, Thylstrup A, Larsen MJ. Rational use of fluorides in caries prevention. A concept based on possible cariostatic mechanisms. Acta Odontol Scand. 1981;39:2419.

Feragen KB, Stock NM. When there is more than a cleft: psychological adjustment when a cleft is associated with an additional condition. Cleft Palate Craniofac J. 2014;51:514.

Feragen KB, Stock NM, Kvalem IL. Risk and Protective Factors at Age 16: Psychological Adjustment in Children With a Cleft Lip and/or Palate. Cleft Palate Craniofac J. 2015;52:555-73.

Flynn T, Lohmander A. A longitudinal study of hearing and middle ear status in individuals with UCLP. Otol Neurotol. 2014;35:989-96.

Gabre P, Norrman C, Birkhed D. Oral sugar clearance in individuals with oral motor dysfunctions. Caries Res. 2005;39:357-62. 
Gassling V, Holterhus PM, Herbers D, Kulle A, Niederberger U, Hedderich J, Wiltfang J, Gerber WD. Stress-coping and cortisol analysis in patients with non-syndromic cleft lip and palate: an explorative study. PLoS One. 2012;7:e41015.

Gilchrist F, Marshman Z, Deery C, Rodd HD. The impact of dental caries on children and young people: what they have to say? Int J Paediatr Dent. 2015;25:327-38.

Gomes AC, Neves LT, Gomide MR. Enamel defects in maxillary central incisors of infants with unilateral cleft lip. Cleft Palate Craniofac J. 2009;46:420-4.

Hagberg C, Larson O, Milerad J. Incidence of cleft lip and palate and risks of additional malformations. Cleft Palate Craniofac J. 1998;35:40-5.

Hanberger L, Ludvigsson J, Nordfeldt S. Health-related quality of life in intensively treated young patients with type 1 diabetes. Pediatr Diabetes. 2009;10:374-81.

Hänsel Petersson G, Twetman S, Bratthall D. Evaluation of a computer program for caries risk assessment in schoolchildren. Caries Res. 2002;36:327-40.

Hansson E, Svensson H, Becker M. Adopted children with cleft lip or palate, or both, require special needs cleft surgery. J Plast Surg Hand Surg. 2012;46:75-9.

Hao Y, Tian S, Jiao X, Mi N, Zhang B, Song T, An L, Zheng X, Zhuang D. Association of Parental Environmental Exposures and Supplementation Intake with Risk of Nonsyndromic Orofacial Clefts: A Case-Control Study in Heilongjiang Province, China. Nutrients. 2015;7:7172-84.

Hasslöf P, Twetman S. Caries prevalence in children with cleft lip and palate--a systematic review of case-control studies. Int J Paediatr Dent. 2007;17:313-9.

Havstam C, Laakso K, Ringsberg KC. Making sense of the cleft. Young adults' accounts of growing up with a cleft and deviant speech. J Health Psychol. 2011;16:22-30.

Hellhammer DH, Wüst S, Kudielka BM. Salivary cortisol as a biomarker in stress research. Psychoneuroendocrinology. 2009;34:163-71.

Hewson AR, McNamara CM, Foley TF, Sandy JR. Dental experience of cleft affected children in the west of Ireland. Int Dent J. 2001;51:73-6.

Hjern A, Rajmil L, Bergström M, Berlin M, Gustafsson PA, Modin B. Migrant density and well-being--a national school survey of 15-year-olds in Sweden. Eur J Public Health. 2013;23:823-8.

Holgerson PL, Twetman S, Stecksén-Blicks C. Validation of an age-modified caries risk assessment program (Cariogram) in preschool children. Acta Odontol Scand. 2009;67:106-12.

Hugoson A, Falk H, Johansson S. Consensus Conference on Caries in the Primary Dentition and its Clinical Management. The Institute for Postgraduate Dental Education; Jönköping, Sweden. Stockholm: Gothia, 2002.

Hunt O, Burden D, Hepper P, Stevenson M, Johnston C. Self-reports of psychosocial functioning among children and young adults with cleft lip and palate. Cleft Palate Craniofac J. 2006;43:598-605.

Isaksson H, Alm A, Koch G, Birkhed D, Wendt LK. Caries prevalence in Swedish 20-yearolds in relation to their previous caries experience. Caries Res. 2013;47:234-42. 
Jacobsson B, Koch G, Magnusson T, Hugoson A. Oral health in young individuals with foreign and Swedish backgrounds--a ten-year perspective. Eur Arch Paediatr Dent. 2011;12:151-8.

Jervaeus A, Kottorp A, Wettergren L. Psychometric properties of KIDSCREEN-27 among childhood cancer survivors and age matched peers: a Rasch analysis. Health Qual Life Outcomes. 2013;11:96.

Jervaeus A, Lampic C, Johansson E, Malmros J, Wettergren L. Clinical significance in selfrated HRQoL among survivors after childhood cancer - demonstrated by anchor-based thresholds. Acta Oncol. 2014;53:486-92.

Jindal A, McMeans M, Narayanan S, Rose EK, Jain S, Marazita ML, Menezes R, Letra A, Carvalho FM, Brandon CA, et al. Women are more susceptible to caries but individuals born with clefts are not. Int J Dent. 2011;2011:454532.

Johnsen DC. Dental caries patterns in preschool children. Dent Clin North Am. 1984;28:3-20.

Johnsen DC, Dixon M. Dental caries of primary incisors in children with cleft lip and palate. Cleft Palate J. 1984;21:104-9.

Johnston L, Vieira AR. Caries experience and overall health status. Oral Health Prev Dent. 2014;12:163-70.

Juffer F, Tieman W. Being adopted Internationally adopted children's interest and feelings. International Social Work. 2009;52:635-47.

Kambalimath HV, Dixit UB, Thyagi PS. Salivary cortisol response to psychological stress in children with early childhood caries. Indian J Dent Res. 2010;21:231-7.

King NM, Wong WL, Wong HM. Caries experience of chinese children with cleft lip and palate. Cleft Palate Craniofac J. 2013;50:448-55.

King SL, Hegadoren KM. Stress hormones: how do they measure up? Biol Res Nurs. 2002;4:92-103.

Kirchberg A, Makuch A, Hemprich A, Hirsch C. Dental caries in the primary dentition of german children with cleft lip, alveolus, and palate. Cleft Palate Craniofac J. 2014;51:308-13.

Kirchberg A, Treide A, Hemprich A. Investigation of caries prevalence in children with cleft lip, alveolus, and palate. J Craniomaxillofac Surg. 2004;32:216-9.

Klingberg G. Dental fear and behavior management problems in children. A study of measurement, prevalence, concomitant factors, and clinical effects. Swed Dent J Suppl. 1995;103:1-78.

Koch FS, Ludvigsson J, Sepa A. Parents' psychological stress over time may affect children's cortisol at age 8. J Pediatr Psychol. 2010;35:950-9.

Kortelainen T, Tolvanen M, Luoto A, Ylikontiola LP, Sandor GK, Lahti S. Comparison of Oral Health-Related Quality of Life Among Schoolchildren With and Without Cleft Lip and/or Palate. Cleft Palate Craniofac J. 2016;53:e172-6.

Kramer FJ, Gruber R, Fialka F, Sinikovic B, Hahn W, Schliephake H. Quality of life in school-age children with orofacial clefts and their families. J Craniofac Surg. 2009;20:2061-6. 
Kuhlthau K, Orlich F, Hall TA, Sikora D, Kovacs EA, Delahaye J, Clemons TE. HealthRelated Quality of Life in children with autism spectrum disorders: results from the autism treatment network. J Autism Dev Disord. 2010;40:721-9.

Kühnisch J, Berger S, Goddon I, Senkel H, Pitts N, Heinrich-Weltzien R. Occlusal caries detection in permanent molars according to WHO basic methods, ICDAS II and laser fluorescence measurements. Community Dent Oral Epidemiol. 2008;36:475-84.

Lages EM, Marcos B, Pordeus IA. Oral health of individuals with cleft lip, cleft palate, or both. Cleft Palate Craniofac J. 2004;41:59-63.

Lee do Y, Kim E, Choi MH. Technical and clinical aspects of cortisol as a biochemical marker of chronic stress. BMB Rep. 2015;48:209-16.

Lee GH, McGrath C, Yiu CK, King NM. A comparison of a generic and oral health-specific measure in assessing the impact of early childhood caries on quality of life.

Community Dent Oral Epidemiol. 2010;38:333-9.

Lee YC, Yang HJ, Chen VC, Lee WT, Teng MJ, Lin CH, Gossop M. Meta-analysis of quality of life in children and adolescents with ADHD: By both parent proxy-report and child self-report using PedsQL. Res Dev Disabil. 2016;51-52:160-72.

Li Y, Navia JM, Bian JY. Prevalence and distribution of developmental enamel defects in primary dentition of Chinese children 3-5 years old. Community Dent Oral Epidemiol. 1995;23:72-9.

Lingström P, Moynihan P. Nutrition, saliva, and oral health. Nutrition. 2003;19:567-9.

LKG-registret (kvalitetsregister för uppföljning av läpp- käk- gomspalt) The Swedish national CLP registry 2016 [Available at: http://rcsyd.se/anslutna-register/the-swedishnational-clp-registry. Accessed September 20, 2016]

Locker D, Jokovic A, Tompson B. Health-related quality of life of children aged 11 to 14 years with orofacial conditions. Cleft Palate Craniofac J. 2005;42:260-6.

Loesche WJ. Role of Streptococcus mutans in human dental decay. Microbiol Rev. 1986;50:353-80.

Lucas VS, Gupta R, Ololade O, Gelbier M, Roberts GJ. Dental health indices and caries associated microflora in children with unilateral cleft lip and palate. Cleft Palate Craniofac J. 2000;37:447-52.

Lunardelli SE, Peres MA. Prevalence and distribution of developmental enamel defects in the primary dentition of pre-school children. Braz Oral Res. 2005;19:144-9.

Maciel SP, Costa B, Gomide MR. Difference in the prevalence of enamel alterations affecting central incisors of children with complete unilateral cleft lip and palate. Cleft Palate Craniofac J. 2005;42:392-5.

Malanczuk T, Opitz C, Retzlaff R. Structural changes of dental enamel in both dentitions of cleft lip and palate patients. J Orofac Orthop. 1999;60:259-68.

Mani M, Carlsson M, Marcusson A. Quality of life varies with gender and age among adults treated for unilateral cleft lip and palate. Cleft Palate Craniofac J. 2010;47:491-8.

Marcusson A, Paulin G, Östrup L. Facial appearance in adults who had cleft lip and palate treated in childhood. Scand J Plast Reconstr Surg Hand Surg. 2002;36:16-23.

Matos-Gomes N, Katsurayama M, Makimoto FH, Santana LL, Paredes-Garcia E, Becker MA, Dos-Santos MC. Psychological stress and its influence on salivary flow rate, total 
protein concentration and IgA, IgG and IgM titers. Neuroimmunomodulation. 2010;17:396-404.

McEwen BS, Seeman T. Protective and damaging effects of mediators of stress. Elaborating and testing the concepts of allostasis and allostatic load. Ann N Y Acad Sci. 1999;896:30-47.

Mejàre I, Axelsson S, Dahlén G, Espelid I, Norlund A, Tranaeus S, Twetman S. Caries risk assessment. A systematic review. Acta Odontol Scand. 2014;72:81-91.

Michels N, Sioen I, Braet C, Eiben G, Hebestreit A, Huybrechts I, Vanaelst B, Vyncke K, De Henauw S. Stress, emotional eating behaviour and dietary patterns in children. Appetite. 2012;59:762-9.

Millar K, Bell A, Bowman A, Brown D, Lo TW, Siebert P, Simmons D, Ayoub A. Psychological status as a function of residual scarring and facial asymmetry after surgical repair of cleft lip and palate. Cleft Palate Craniofac J. 2013;50:150-7.

Mitchell LE. Genetic epidemiology of birth defects: nonsyndromic cleft lip and neural tube defects. Epidemiol Rev. 1997;19:61-8.

Molina-Solana R, Yanez-Vico RM, Iglesias-Linares A, Mendoza-Mendoza A, Solano-Reina E. Current concepts on the effect of environmental factors on cleft lip and palate. Int $J$ Oral Maxillofac Surg. 2013;42:177-84.

Montero MJ, Douglass JM, Mathieu GM. Prevalence of dental caries and enamel defects in Connecticut Head Start children. Pediatr Dent. 2003;25:235-9.

Moynihan P, Petersen PE. Diet, nutrition and the prevention of dental diseases. Public Health Nutr. 2004;7:201-26.

Moynihan PJ, Kelly SA. Effect on caries of restricting sugars intake: systematic review to inform WHO guidelines. J Dent Res. 2014;93:8-18.

Mueller AA, Kalak N, Schwenzer-Zimmerer K, Holsboer-Trachsler E, Brand S. Cortisol levels and sleep patterns in infants with orofacial clefts undergoing surgery. Neuropsychiatr Dis Treat. 2014;10:1965-72.

Nationella kvalitetsregistret. Cohens kappa: Sveriges kommuner och landsting; 2016 [Available at: http://www.kvalitetsregister.se/. Accessed October 14, 2016]

Nickel MK, Muehlbacher M, Kaplan P, Krawczyk J, Buschmann W, Kettler C, Rother N, Egger C, Rother WK, Loew TK, et al. Influence of family therapy on bullying behaviour, cortisol secretion, anger, and quality of life in bullying male adolescents: A randomized, prospective, controlled study. Can J Psychiatry. 2006;51:355-62.

Nordenram G. Dental health: Health in Sweden: The National Public Health Report 2012. Chapter 16. Scand J Public Health. 2012;40:281-6.

Norderyd O, Koch G, Papias A, Köhler AA, Helkimo AN, Brahm CO, Lindmark U, Lindfors N, Mattsson A, Rolander B, et al. Oral health of individuals aged 3-80 years in Jonkoping, Sweden during 40 years (1973-2013). II. Review of clinical and radiographic findings. Swed Dent J. 2015;39:69-86.

Nyberg J, Havstam C. Speech in 10-Year-Olds Born With Cleft Lip and Palate: What Do Peers Say? Cleft Palate Craniofac J. 2016;53:516-26. 
Nyberg J, Peterson P, Lohmander A. Speech outcomes at age 5 and 10 years in unilateral cleft lip and palate after one-stage palatal repair with minimal incision technique - a longitudinal perspective. Int J Pediatr Otorhinolaryngol. 2014;78:1662-70.

Oliveira AF, Chaves AM, Rosenblatt A. The influence of enamel defects on the development of early childhood caries in a population with low socioeconomic status: a longitudinal study. Caries Res. 2006;40:296-302.

Omma L, Petersen S. Health-related quality of life in indigenous Sami schoolchildren in Sweden. Acta Paediatr. 2015;104:75-83.

Oscarson N, Källestål C, Lindholm L. A pilot study of the use of oral health-related quality of life measures as an outcome for analysing the impact of caries disease among Swedish 19-year-olds. Caries Res. 2007;41:85-92.

Pani SC, Al Odhaib M. The impact of dental treatment on the salivary cortisol levels of children with severe early childhood caries. Eur Arch Paediatr Dent. 2013.

DOI: $10.1007 /$ s40368-013-0083-y

Paul T, Brandt RS. Oral and dental health status of children with cleft lip and/or palate. Cleft Palate Craniofac J. 1998;35:329-32.

Paula JS, Meneghim MC, Pereira AC, Mialhe FL. Oral health, socio-economic and home environmental factors associated with general and oral-health related quality of life and convergent validity of two instruments. BMC Oral Health. 2015;15:26.

Peasgood T, Bhardwaj A, Biggs K, Brazier JE, Coghill D, Cooper CL, Daley D, De Silva C, Harpin V, Hodgkins P, et al. The impact of ADHD on the health and well-being of ADHD children and their siblings. Eur Child Adolesc Psychiatry. 2016.

DOI: $10.1007 / \mathrm{s} 00787-016-0841-6$

Petersen PE. The World Oral Health Report 2003, Continous improvement of oral health in the 21 st century - the approach of the WHO Global Oral Health Programme. Community Dent Oral Epidemiol. 2003 Dec;31 Suppl 1:3-23.

Petersen PE, Bourgeois D, Ogawa H, Estupinan-Day S, Ndiaye C. The global burden of oral diseases and risks to oral health. Bull World Health Organ. 2005;83:661-9.

Pisula E, Lukowska E, Fudalej PS. Self-esteem, coping styles, and quality of life in polish adolescents and young adults with unilateral cleft lip and palate. Cleft Palate Craniofac J. 2014;51:290-9.

Pitts N, Ekstrand K, Foundation I. International Caries Detection and Assessment System (ICDAS) and its International Caries Classification and Management System (ICCMS) - methods for staging of the caries process and enabling dentists to manage caries. Community Dent Oral Epidemiol. 2013;41:e41-52.

Ponte E, Tabaj D, Maglione M, Melato M. Diabetes mellitus and oral disease. Acta Diabetol. 2001;38:57-62.

Pruessner JC, Kirschbaum C, Meinlschmid G, Hellhammer DH. Two formulas for computation of the area under the curve represent measures of total hormone concentration versus time-dependent change. Psychoneuroendocrinology. 2003;28:916-31.

Queiroz Herkrath AP, Herkrath FJ, Rebelo MA, Vettore MV. Measurement of health-related and oral health-related quality of life among individuals with nonsyndromic orofacial 
clefts: a systematic review and meta-analysis. Cleft Palate Craniofac J. 2015;52:15772.

Quigley GA, Hein JW. Comparative cleansing efficiency of manual and power brushing. $J$ Am Dent Assoc. 1962;65:26-9.

Raadal M, Strand GV, Amarante EC, Kvale G. Relationship between caries prevalence at 5 years of age and dental anxiety at 10. Eur J Paediatr Dent. 2002;3:22-6.

Rai K, Hegde AM, Shetty S, Shetty S. Estimation of salivary cortisol in children with rampant caries. J Clin Pediatr Dent. 2010;34:249-52.

Ranta R. A review of tooth formation in children with cleft lip/palate. Am J Orthod Dentofacial Orthop. 1986;90:11-8.

Ravens-Sieberer U, Gosch A, Erhart M, Auquier P, von Rueden U, Nickel J, Kurth B-M, Duer W, Fuerth K, Czemy L, et al. The KIDSCREEN questionnaires. Quality of life questionnaire for children and adolescents. Handbook. Lengerich: Pabst science; 2006.

Ravens-Sieberer U, Gosch A, Rajmil L, Erhart M, Bruil J, Duer W, Auquier P, Power M, Abel T, Czemy L, et al. KIDSCREEN-52 quality-of-life measure for children and adolescents. Expert Rev Pharmacoecon Outcomes Res. 2005;5:353-64.

Ravens-Sieberer U, Herdman M, Devine J, Otto C, Bullinger M, Rose M, Klasen F. The European KIDSCREEN approach to measure quality of life and well-being in children: development, current application, and future advances. Qual Life Res. 2014;23:791-803.

Reddy S, Kaul S, Prasad M, Agnihotri J, Amudha D, Vinayak R. Interlink between stress and periodontal disease. Stress and periiodontal disease. 2012;10:126-31.

Rose E, Staats R, Thissen U, Otten JE, Schmelzeisen R, Jonas I. Sleep-related obstructive disordered breathing in cleft palate patients after palatoplasty. Plast Reconstr Surg. 2002;110:392-6.

Sagheri D, Ravens-Sieberer U, Braumann B, von Mackensen S. An Evaluation of HealthRelated Quality of Life (HRQoL) in a group of 4-7 year-old children with cleft lip and palate. J Orofac Orthop. 2009;70:274-84.

Sakeenabi B, Hiremath SS. Dental caries experience and salivary Streptococcus mutans, lactobacilli scores, salivary flow rate, and salivary buffering capacity among 6-yearold Indian school children. J Int Soc Prev Community Dent. 2011;1:45-51.

Salanitri S, Seow WK. Developmental enamel defects in the primary dentition: aetiology and clinical management. Aust Dent J. 2013;58:133-40; quiz 266.

Sekhon PS, Ethunandan M, Markus AF, Krishnan G, Rao CB. Congenital anomalies associated with cleft lip and palate-an analysis of 1623 consecutive patients. Cleft Palate Craniofac J. 2011;48:371-8.

Selwitz RH, Ismail AI, Pitts NB. Dental caries. Lancet. 2007;369:51-9.

Seow WK. Developmental defects of enamel and dentine: challenges for basic science research and clinical management. Aust Dent J. 2014;59 Suppl 1:143-54.

Sheahan P, Miller I, Sheahan JN, Earley MJ, Blayney AW. Incidence and outcome of middle ear disease in cleft lip and/or cleft palate. Int J Pediatr Otorhinolaryngol.

2003;67:785-93. 
Shklair IL, Englander HR, Stein LM, Kesel RG. Preliminary report on the effect of complete mouth rehabilitation on oral lactobacilli counts. J Am Dent Assoc. 1956;53:155-8.

Sivertsen TB, Assmus J, Greve G, Åstrøm AN, Skeie MS. Oral health among children with congenital heart defects in Western Norway. Eur Arch Paediatr Dent. 2016;17:397406.

Skeie MS, Riordan PJ, Klock KS, Espelid I. Parental risk attitudes and caries-related behaviours among immigrant and western native children in Oslo. Community Dent Oral Epidemiol. 2006;34:103-13.

Skuladottir H, Sivertsen A, Assmus J, Remme AR, Dahlen M, Vindenes H. Hearing outcomes in patients with cleft lip/palate. Cleft Palate Craniofac J. 2015;52:e23-31.

Sneeuw KC, Sprangers MA, Aaronson NK. The role of health care providers and significant others in evaluating the quality of life of patients with chronic disease. $J$ Clin Epidemiol. 2002;55:1130-43.

Socialstyrelsen. Karies hos barn och ungdomar, en lägesrapport för år 2008. 2008:2010-3-5. [Available at: www.socialstyrelsen.se/Lists/Artikelkatalog/Attachments/17949/20103-5.pdf. Accessed October 14, 2016]

Socialstyrelsen. Karies hos barn och ungdomar, Epidemiologiska uppgifter för år 2014. 2015. [Available at: www.socialstyrelsen.se/Lists/Artikelkatalog/Attachments/19993/201511-36.pdf. Accessed October 14, 2016]

Socialstyrelsen. Ovanliga diagnoser 2016 [Available at: www.socialstyrelsen.se/rarediseases. Accessed October 14, 2016]

Stec-Slonicz M, Szczepanska J, Hirschfelder U. Comparison of caries prevalence in two populations of cleft patients. Cleft Palate Craniofac J. 2007;44:532-7.

Stecksén-Blicks C, Hasslöf P, Kieri C, Widman K. Caries and background factors in Swedish 4-year-old children with special reference to immigrant status. Acta Odontol Scand. 2014;72:852-8.

Stecksén-Blicks C, Rydberg A, Nyman L, Asplund S, Svanberg C. Dental caries experience in children with congenital heart disease: a case-control study. Int J Paediatr Dent. 2004; 14:94-100.

Stock NM, Feragen KB, Rumsey N. "It Doesn't All Just Stop at 18": Psychological Adjustment and Support Needs of Adults Born With Cleft Lip and/or Palate. Cleft Palate Craniofac J. 2015;52:543-54.

Svedberg P, Eriksson M, Boman E. Associations between scores of psychosomatic health symptoms and health-related quality of life in children and adolescents. Health Qual Life Outcomes. 2013;11:176.

Tannure PN, Soares FM, Kuchler EC, Motta LG, Costa MC, Granjeiro JM. Measuring the impact of quality of life of children treated for orofacial clefts: a case-control study. $J$ Clin Pediatr Dent. 2013;37:381-4.

Targino AG, Rosenblatt A, Oliveira AF, Chaves AM, Santos VE. The relationship of enamel defects and caries: a cohort study. Oral Dis. 2011;17:420-6.

ten Cate JM. Contemporary perspective on the use of fluoride products in caries prevention. Br Dent J. 2013;214:161-7. 
The World Health Organization Quality of Life assessment. The World Health Organization Quality of Life assessment (WHOQOL): position paper from the World Health Organization. Soc Sci Med. 1995;41:1403-9.

Tomarken AJ, Han GT, Corbett BA. Temporal patterns, heterogeneity, and stability of diurnal cortisol rhythms in children with autism spectrum disorder.

Psychoneuroendocrinology. 2015;62:217-26.

Törnhage CJ. Reference values for morning salivary cortisol concentrations in healthy schoolaged children. J Pediatr Endocrinol Metab. 2002;15:197-204.

Törnhage CJ, Alfvén G. Diurnal salivary cortisol concentration in school-aged children: increased morning cortisol concentration and total cortisol concentration negatively correlated to body mass index in children with recurrent abdominal pain of psychosomatic origin. J Pediatr Endocrinol Metab. 2006;19:843-54.

Turesky S, Gilmore ND, Glickman I. Reduced plaque formation by the chloromethyl analogue of victamine C. J Periodontol. 1970;41:41-3.

Turner C, Zagirova AF, Frolova LE, Courts FJ, Williams WN. Oral health status of Russian children with unilateral cleft lip and palate. Cleft Palate Craniofac J. 1998;35:489-94.

Turvey TA, Vig KWL, Fonseca RJ, editors. Facial clefts and craniosynostosis: principles and management. Philadelphia: Saunders; 1996

van Houte J. Bacterial specificity in the etiology of dental caries. Int Dent J. 1980;30:305-26.

Ward JA, Vig KW, Firestone AR, Mercado A, da Fonseca M, Johnston W. Oral health-related quality of life in children with orofacial clefts. Cleft Palate Craniofac J. 2013;50:17481.

Vargas-Ferreira F, Salas MM, Nascimento GG, Tarquinio SB, Faggion CM, Jr., Peres MA, Thomson WM, Demarco FF. Association between developmental defects of enamel and dental caries: A systematic review and meta-analysis. J Dent. 2015;43:619-28.

Varni JW, Limbers CA, Burwinkle TM. Impaired health-related quality of life in children and adolescents with chronic conditions: a comparative analysis of 10 disease clusters and 33 disease categories/severities utilizing the PedsQL 4.0 Generic Core Scales. Health Qual Life Outcomes. 2007;5:43.

Wehby GL, Murray JC. Folic acid and orofacial clefts: a review of the evidence. Oral Dis. 2010;16:11-9.

Wennström B, Törnhage CJ, Nasic S, Hedelin H, Bergh I. The perioperative dialogue reduces postoperative stress in children undergoing day surgery as confirmed by salivary cortisol. Paediatr Anaesth. 2011;21:1058-65.

Wong FW, King NM. The oral health of children with clefts--a review. Cleft Palate Craniofac J. 1998;35:248-54.

Wong KW, Forrest CR, Goodacre TE, Klassen AF. Measuring outcomes in craniofacial and pediatric plastic surgery. Clin Plast Surg. 2013;40:305-12.

Wright JT. Defining the contribution of genetics in the etiology of dental caries. $J$ Dent Res. 2010;89:1173-4.

Zero DT. Sugars - the arch criminal? Caries Res. 2004;38:277-85.

Zhu WC, Xiao J, Liu Y, Wu J, Li JY. Caries experience in individuals with cleft lip and/or palate in China. Cleft Palate Craniofac J. 2010;47:43-7. 


\section{Papers}

The articles associated with this thesis have been removed for copyright reasons. For more details about these see:

http://urn.kb.se/resolve?urn=urn:nbn:se:liu:diva- 132623 